University of Rhode Island

DigitalCommons@URI

Open Access Dissertations

2021

\title{
CO-OCCURRENCE OF DEPRESSIVE SYMPTOMS AND ALCOHOL USE: IMPACT OF SOCIODEMOGRAPHIC FACTORS
}

Marie C. Tate

University of Rhode Island, marie_tate15@uri.edu

Follow this and additional works at: https://digitalcommons.uri.edu/oa_diss

\section{Recommended Citation}

Tate, Marie C., "CO-OCCURRENCE OF DEPRESSIVE SYMPTOMS AND ALCOHOL USE: IMPACT OF SOCIODEMOGRAPHIC FACTORS" (2021). Open Access Dissertations. Paper 1258.

https://digitalcommons.uri.edu/oa_diss/1258

This Dissertation is brought to you for free and open access by DigitalCommons@URI. It has been accepted for inclusion in Open Access Dissertations by an authorized administrator of DigitalCommons@URI. For more information, please contact digitalcommons-group@uri.edu. 
CO-OCCURRENCE OF DEPRESSIVE SYMPTOMS AND ALCOHOL USE: IMPACT OF SOCIODEMOGRAPHIC FACTORS

\author{
BY \\ MARIE TATE \\ A DISSERTATION SUBMITTED IN PARTIAL FULFILLMENT OF THE \\ REQUIREMENTS FOR THE DEGREE OF \\ DOCTOR OF PHILOSOPHY \\ IN \\ BEHAVIORAL SCIENCE, PSYCHOLOGY
}

UNIVERSITY OF RHODE ISLAND

2021 
DOCTOR OF PHILOSOPHY DISSERTATION

\author{
OF \\ MARIE TATE
}

APPROVED:

Dissertation Committee:

\author{
Major Professor: Andrea Paiva \\ Inside Committee Member: Lynda Stein \\ Outside Committee Member: Bryan Blissmer \\ Brenton DeBoef \\ DEAN OF THE GRADUATE SCHOOL
}

UNIVERSITY OF RHODE ISLAND

2021 


\begin{abstract}
Since depression disorders have been found to be the leading cause of disability (Friedrich, 2017), affecting 17.3 million adults in the United States alone (National Institute of Mental Health, 2017). Various scales have been developed to measure depression. The National Survey on Drug Use and Health uses the Major Depression Episode module to measure lifetime depression symptoms, this is the scale the current work aims to validate. The selected model had adequate fit. It was also found to be invariant at the strictest level across gender, race, income, and education level. The validated scale was then used to study the relationship between depression and alcohol use. The comorbidity of depression and alcohol use has been common in our society for many years (Floud et al., 2015). The purpose of the current study is to investigate the role that race, gender, and socioeconomic status have on the comorbidity between depression and alcohol use. There were differences between depression symptoms and alcohol use on the socioeconomic demographics. However, there were no moderation effects. This indicates that sociodemographics do play a role in both depression symptoms and alcohol use, even though they do not change the relationship. The implications of these studies are two-fold, it sets up future research to be done people who may not have depression but screen into a depression scale to determine how these factors effect.
\end{abstract}




\section{ACKNOWLEDGEMENTS}

Thank you to my Major Professor, Andrea Paiva, for taking me on as a student and working with me as my research interest changed over the years. Thank you to my committee members, Lynda Stein and Bryan Blissmer, for supporting me through the unfortunate loss of Wayne Velicer and always supporting my research ideas. 


\section{PREFACE}

The below dissertation is in manuscript format. There are two manuscripts being prepared, both are in preparation stages. The first manuscript will be submitted to the Journal of Public Health and will be titled, Validation of Major Depressive Episode Module Across Gender, Race, Income, and Education Level. The second manuscript will be submitted to the Journal of Cross-Cultural Psychology and will be titled, Cooccurance of Depressive Symptoms and Alcohol Use: The Impact of Sociodemographic Factors. Marie Tate will be first author on both manuscripts, followed be Andrea Paiva, Lynda Stein, and Bryan Blissmer. The first manuscript validates a depression scale, while the second expands from the first and uses the validated depression scale in a moderation analysis. Both manuscripts focus on depression, race, gender, and socioeconomic status. The second manuscripts investigates how the demographic factors influence the relationship between depression and alcohol use. 


\section{TABLE OF CONTENTS}

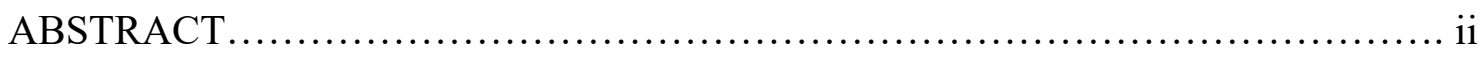

ACKNOWLEDGEMENTS.........................................................

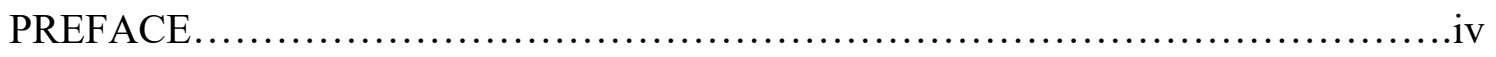

TABLE OF CONTENTS ........................................................

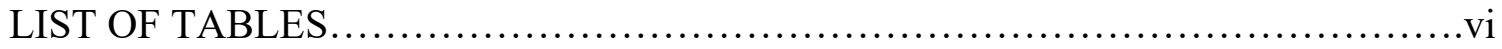

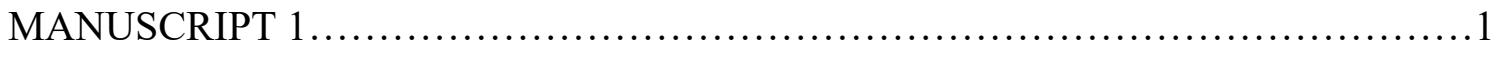

REFERENCES.......................................................

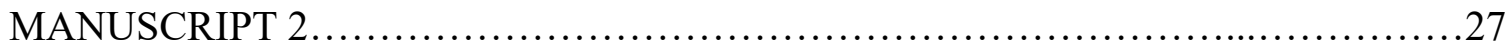

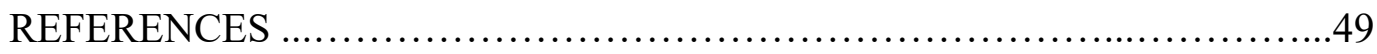

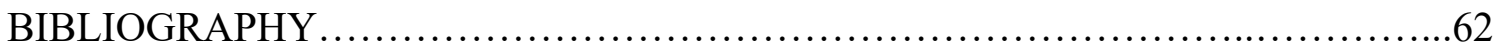




\section{LIST OF TABLES}

TABLE

PAGE

Manuscript 1 Tables....................................................23

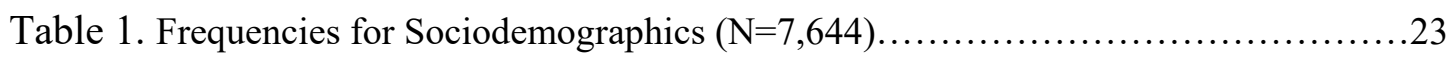

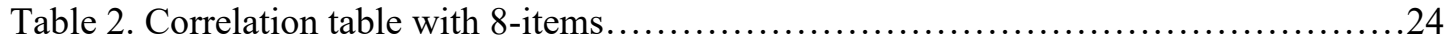

Table 3. Major Depressive Episode Scale 1-Factor standardized loadings...................24

Table 4. Invariance Test results for Gender.........................................25

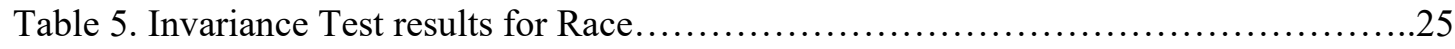

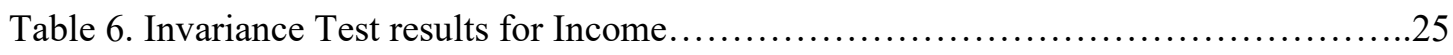

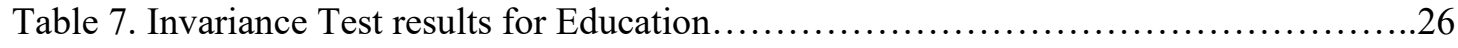

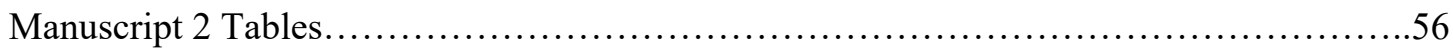

Table 1. Frequencies for Sociodemographics w/o Alcohol Consumption $(\mathrm{N}=7,644) \ldots \ldots \ldots . .56$

Table 2. Descriptive Statistics.................................................. 56

Table 3. Correlation Table with alcohol consumption...............................57

Table 4. Descriptive statistics without Alcohol Consumption...........................57

Table 5. Correlation Table without alcohol consumption.............................58

Table 6. Moderation between depression and binge drinking with $\mathrm{X}$ as the focal moderator..59

Table 7. ANOVAs and T-test with depression as the outcome variable....................60

Table 8. ANOVAs and T-tests with Binge Drinking as the outcome variable................61 


\section{MANUSCRIPT -1}

In preparation for Journal of Public Health

Validation of Major Depressive Episode Module Across Gender, Race, Income, and Education Level

Marie Tate, Andrea Paiva, Lynda Stein, and Bryan Blissmer

Psychology, University of Rhode Island, Kingston, RI

Kinesiology, University of Rhode Island, Kingston, RI

Corresponding Author: Marie Tate, Ph.D.

Psychology Department

University of Rhode Island

142 Flagg Rd

Kingston, RI 02881

Phone: 540-604-7021

Email address: marie tate15@uri.edu 


\begin{abstract}
Depression disorders were found to be the leading cause of disability in 2017 (Friedrich, 2017), affecting 17.3 million adults in their lifetime in the United States alone (National Institute of Mental Health, 2017). Various scales are used to measure depression. The National Survey on Drug Use and Health uses the Major Depression Episode module to measure lifetime depression symptoms. The current study investigates the factor structure and invariance of the module across gender, race, income, and education level. The results found that a 1-factor model fit adequately. The module also was found to be invariant at the strictest level across gender, race, income, and education level. These results support the comparison of the depression module across different gender, race, income, and education levels.
\end{abstract}


Validation of Major Depressive Episode Module Across Gender, Race, Income, and Education Level

For the last 27 years, depressive disorders have been one of the top four leading disabilities that people live with globally (GBD 2017 Disease and Injury Incidence and Prevalence Collaborators, 2018). In 2017 it was found to be the leading cause of disability, impacting 322 million people (Friedrich, 2017). In the United States, approximately 17.3 million (7.1\%) adults have experienced at least one major depressive episode (MDE) in their lifetime (National Institute of Mental Health "Major Depression”, 2017). Depression is defined as experiencing five or more depressive symptoms within a two-week period of time, with at least one symptom being either "depressed mood" or "loss of interest or pleasure" (American Psychiatric Association (APA), 2013). There are many ways that researchers can measure depression, one scale used is the National Comorbidity Survey - Replication (NCS-R) depression module (Kessler et al., 2003; Fava et al., 2010; Borges et al., 2006). This module was developed based on the DSM-IV criteria for depression (Substance Abuse and Mental Health Services Administration (SAMHSA), 2019). The U.S. administers a National Survey on Drug Use and Health (NSDUH) annually that collects data from people throughout all 50 states, The District of Columbia (D.C.), and Puerto Rico (SAMHSA, 2019). The NSDUH uses an adapted version of the NCS-R to measure if a person has had a major depressive episode in their lifetime. The adapted NCS-R depression module from the NSDUH is one of the primary sources used to present population-based estimates of MDE (Kessler et al., 2005). SAMHSA uses these data to update the MDE estimates on a national level annually. It can also be used to shape policies at the national, state, and local levels. The validation of 
a scale utilized in a national sample is important for population estimates and policy work at the state and federal level.

The purpose of the current paper is to provide support for using the MDE module in the NSDUH as a one-factor latent variable. Since the data collected are from all 50 states, D.C., and Puerto Rico, the sample is consistently diverse in gender, race, and socioeconomic status (SES). Accordingly, a psychometric validation of the module will be done to compare gender, racial groups, and SES.

Depression affects people of any gender, race, or SES (Foulds et al., 2015; Gierisch et al., 2011; Holahan et al., 2003; Swendsen et al., 2000). Past research provides support for depression scales being a 1-factor model in various scales (Ryan et al., 2013; Feldman, 1993). Ryan et al. (2013) found a 1-factor model for the Patient Health Questionnaire 9-item. Feldman (1993) investigated fit on various depression and anxiety models and found that fit between a 1-factor and 2-factor depression scale was not significant. Ensuring that a depression module in a nationwide survey records the same information across these different groups is important. Differences in depression are prevalent between males and females. Females are more likely than males to report depressive symptoms (Angst et al., 2002; Kuehner, 2013; Major Depression, 2019). The prevalence of depression was found to be $8.7 \%$ among females while in males it was only 5.3\% in the NSDUH data from 2017 (Major Depression, 2019). According to Angst et al. (2002), the reasoning behind this difference is very complex. One theory proposed was, females report more symptoms on the depression scale than males do, meaning males could be impaired and report fewer symptoms even with the same level of depression (Angst et al., 2002). Angst et al. (2002) theorized that this could indicate that males have 
a lower threshold of depression symptoms than females do (Angst et al., 2002). There was no evidence to suggest that depression symptoms would be different between males and females, therefore there should be invariance across the sexes for the NCS-R. Past research (Byrne et al., 1993; Fonseca-Pedrero et al., 2010) suggests that various depression scales are invariant across sexes as well, increasing support that the NCS-R is invariant. Investigating the invariance of the NCS-R between females and males can provide support that the module is measuring depression symptom accurately between sexes.

Past literature (Alegria et al., 2008; Hankerson et al., 2011) also supports that White people are more likely than other race to report having depressive symptoms. There are multiple explanations for this, including how symptoms present (Alegria et al., 2008; Escobar \& Gorey, 2018; Bailey et al., 2019) and cultural background (Alegria et al., 2008; Escobar \& Gorey, 2018; Bailey et al., 2019). Studies have found that the prevalence of depression among Caucasians is $17.9 \%$ compared to African Americans whose prevalence is $10.4 \%$ (Alegria et al., 2008). Although the prevalence seems to be higher in the Caucasian sample, the African American sample has been more effected by chronic depression $56 \%$ compared to $38.6 \%$ of the Caucasian sample (Alegria et al., 2008). There are various reasons for this difference, one possibility for the different levels of prevalence is the rate at which seeking treatment happens. African Americans tend to seek treatment less often than Caucasian's leading to depression in African American's being undiagnosed or misdiagnosed more frequently (Alegria et al., 2008; Bailey et al., 2019). However, aside from these differences other work found that depression symptoms do not vary be race (Hankerson et al., 2011). It is theorized that 
somatic symptoms are more common in the Black community because it is more culturally acceptable for somatic symptoms to appear than cognitive symptoms (Alegria et al., 2008). Cultural barriers also impact the way Hispanic people report or seek treatment for depression as well (Escobar \& Gorey, 2018). Escobar and Gorey (2018) conducted a meta-analysis investigating the Hispanic cultures impact on depression treatment in the United States. It was found that throughout the eight randomized control trials and one quasi-experimental study, that adapting depression treatment to account for Hispanic culture reduced depression levels over the course of treatment (Escobar \& Gorey, 2018). With cultural differences and the possibility of symptoms being reported differently, testing the invariance of the depression module used in the NSDUH could be valuable.

Lastly, the difference in reporting depression symptoms is also found between different SES levels, although less research has been done with the factor. Research has found that people in higher SES report more depression symptoms (Inaba et al. 2005; Goodman \& Huang, 2002). People in high SES levels may be more likely to report depression symptoms because they are able to worry about their mental wellbeing beyond physical needs (Inaba et al., 2005). Inaba et al. (2005) found a negative correlation between depressive symptoms and income level, indicating that people with lower incomes reported more depressive symptoms. For people who experience food insecurity, housing security, or physical safety, their mental state may not be at the forefront of their thoughts. Studying invariance between different levels of SES will be done by looking at two factors, income levels and education levels. It is important to account for multiple 
SES factors if possible (Goodman \& Huang, 2002). Due to the differences in depression levels and lack of research on this topic, invariance testing would be valuable.

There is a lack of research investigating the factor structure and invariance of the MDE module in the NSDUH. In order to compare depression symptoms across demographics, it is important to ensure consistency of the measurement. The current study will investigate the factor structure of the MDE module within the NSDUH and then test the invariance of the factor structure across various sociodemographics. The MDE module is expected to be a 1-factor structure. Once the structure is validated, multiple invariance tests will be conducted to determine if comparison across groups is possible.

Methods

National Survey on Drug Use and Health (NSDUH)

The data for the current study will come from the NSDUH (SAMHSA, 2019), which is used to track specific substance use, mental health problems, treatments, and other health-related information. Data are collected annually using an independent, multistage area probability sample within each of the 50 states and the District of Columbia. People are excluded from the study if they are active military employees. There are no requirements for having used substances or experienced mental health issues. The NSDUH collects data from people 12 and older, however due to differences in the depression questionnaire, the current study will use data from only participants 18 and older. The survey is administered via an audio computer-assisted self-interviewing system (Hedden et al., 2012). For a more detailed description of how data was collected 
view the "Results from the 2018 National Survey on Drug Use and Mental Health: Summary of National Findings" (SAMHSA, 2019).

Sample

The current study will use a sample of all participants 18 and older from the 2018 NSDUH who completed the Major Depression Episode module (SAMHSA, 2019). There were 7,644 participants, there were 4,866 (63.7\%) females and 2,778 (36.3\%) males. The majority of the sample was non-Hispanic White 5,274 (69\%), followed by Hispanic 1,037 (13.6\%), and non-Hispanic Black/ African American 643 (8.4\%), the remaining races, Asian, Native American, Native Alaskan, Pacific Islanders, and more than one race were less than $5 \%$ of the sample, $690(9 \%)$.

Measures- Major Depression Episode Module

In 2004, an adapted version of the NCS-R (Harvard School of Medicine, 2005) was included in the NSDUH in order to measure lifetime MDE. The minor revisions were made to reduce the length and modify questions for the audio computer-assisted self-interviewing format. The MDE module asked nine questions about depression symptoms, (1) depressed mood most of the day; (2) markedly diminished interest or pleasure in all or almost all activities most of the day; (3) significant weight loss when not sick or dieting, weight gain when not pregnant or growing, or decrease or increase in appetite; (4) insomnia or hypersomnia; (5) psychomotor agitation; (6) fatigue or loss of energy; (7) feelings of worthlessness; (8) diminished ability to think or concentrate or indecisiveness; and (9) recurrent thoughts of death or suicidal ideation (APA, 1994).

Sex 
For the multiple group CFA, gender was asked in the NSDUH but recoded into sex. For the current study we will be using sex with male and female being the categories.

Race

For the multiple group CFA investigated validation across racial groups. Racial groups were categorized by non-Hispanic White, non-Hispanic Black/ African American, non-Hispanic Native American/ Alaskan Native, non-Hispanic Native Hawaiian/ Other Pacific Islander, non-Hispanic Asian, non-Hispanic more than one race, and Hispanic. For the current study, we recoded the racial categories into non-Hispanic White, nonHispanic Black/ African American, and Hispanic, and all other because they were the three largest racial/ ethnicity groups and the rest were below 5\% so they were grouped together.

Income

To investigate the validation of the MDE module across family income levels, income was categorized as (1) less than $\$ 20,000$, (2) $\$ 20,000-\$ 49,999$, (3) $\$ 50,000$ $\$ 74,999$, and (4) $\$ 75,000$ or more.

Education Level

To investigate the validation of the MDE module across education levels, the categories included, (1) less than high school, (2) high school graduate, (3) some college/ associate degree, and (4) college graduate.

Confirmatory Factor Analysis 
Since the MDE module used in the NSDUH was adapted from the NCS-R, a factor analysis was performed to investigate the properties of the measure. A confirmatory factor analysis (CFA) was conducted to validate the use of the MDE module as a latent variable. Using the MDE as a latent construct will increase the reliability, variability, and the correlations with other factors, which will make it easier to work with. Other benefits of determining the factor structure include and reducing confounding variance. A 1-factor model was selected due to past literature that supports all items being part of one scale through a random sample of people both with and without depression (Kessler et al., 2003), it is also the most parsimonious factor structure. When looking at the factor loadings on the 1-factor model, item 1 was the only factor to load below .3, therefore it was dropped. A CFA was then conducted using diagonal weighted least squares (DWLS) estimation on the remaining 8-item 1-factor solution. The DWLS estimation was used since this method accounts for categorical items. After the CFA was conducted, three separate multiple group CFAs (MG-CFA) were implemented using the DWLS estimation. The model fit was evaluated by the chi-square value, comparative fit index (CFI), root mean square error of approximation (RMSEA) with a $90 \%$ confidence interval, and the standardized root mean square residual (SRMR) for each group separately to ensure the same factor structure held. In order to have acceptable fit, a CFI of .90 or greater (Hu \& Bentler, 1999), RMSEA of .06 or less (Hu \& Bentler, 1999), and a SRMR. In order to test the factorial invariance across racial groups, gender, income level, and education level, a multiple group CFA (MGCFA) was conducted. The test was conducted based on the common four-step approach, which entails testing configural invariance (i.e., testing overall factor structure with no equality 
constraints), metric invariance (i.e., factor loadings constrained to be equal across groups), scalar invariance (i.e., threshold constrained to be equal across groups), and strict (i.e., residuals constrained to be equal across groups). If these requirements were met than little to no measurement bias exists when comparing across these groups and latent means can be meaningfully compared (Milfont \& Fischer, 2010). Fit indices were used to determine if metric and scalar invariance held with the following criteria: CFI decreased less than .01, the RMSEA increased by no more than .015, and the SRMR increases by no more than .030 (Putnick \& Bornstein, 2016). The analyses were done on RStudio version 1.3.1073 (RStudio Team, 2020).

The most commonly used measurement equivalence test is confirmatory factor analysis (CFA). When conducting an invariance test, there are four levels of equivalence, configural, metric, scalar, and strict/residual. Each model builds on parameters that are restricted and each model builds on the other in a hierarchal way. Configural is the least restrictive model, the factor structure is set to be the same for each group. When factor loadings are held invariant across groups, metric invariance is being tested. The third step is scalar invariance, this is where the thresholds are being held invariant. Then strict, which is where the residuals are held invariant. If strict invariance is met, then it can be assumed that the scale is measuring the same thing and can be compared between groups. Since the MDE module is binary (yes/ no responses), diagonally weighted least squares will be used as the estimator instead of maximum likelihood estimation.

Reliability

Reliability was measured using Cronbach alphas estimation on the scale. 
Results

CFA

A CFA was conducted on the 8-item 1-factor solution. Normality was tested, each item was found to be normally distributed. Each item was correlated with each other (see table 2). The CFA used the diagonally weighted least squares (DWLS) estimator to account for the binary responses for the MDE items. The fit was found to be acceptable, $\chi^{2}=592.30, \mathrm{p}<.05, \mathrm{CFI}=.913, \mathrm{RMSEA}=.062(.058, .066), \mathrm{SRMR}=.074$. All standardized loadings fit the one factor model above .3 , see table 4 for the standardized factor loadings.

\section{MGCFA - Gender}

The gender variable was recoded to sex in the NSDUH. There were 4,786 females and 2,696 males used in the model due to missing data. The configural model showed adequate fit across both genders, $\chi^{2}=605.88, \mathrm{p}<.001, \mathrm{CFI}=.912, \mathrm{RMSEA}=.062(.057$, $.066), \mathrm{SRMR}=.077$. The metric model did not significantly deteriorate, $\chi^{2}=587.74$, $\mathrm{p}<.001, \mathrm{CFI}=.916, \mathrm{RMSEA}=.055(.052, .060), \mathrm{SRMR}=.078$. The scalar model also did not deteriorate, $\chi^{2}=645.04, \mathrm{p}<.001, \mathrm{CFI}=.907, \mathrm{RMSEA}=.059(.055, .063), \mathrm{SRMR}=$ .079. The scalar model with residuals constrained also did not significantly deteriorate, $\chi^{2}$ $=645.04, \mathrm{p}<.001, \mathrm{CFI}=.907, \mathrm{RMSEA}=.059(.055, .063), \mathrm{SRMR}=.079$. The results revealed there was invariance at the strict level for MDE between males and females (see table 5).

MG CFA - Race

The race variable was recoded into four categories, non-Hispanic White, nonHispanic Black/African American, Hispanic, and all other races. There were 5,274 nonHispanic White, 643 non-Hispanic Black/African American, 1,037 Hispanic, and 690 all 
other races used in the model due to missing data. The configural model showed adequate fit, $\chi^{2}=620.09, \mathrm{p}<.001, \mathrm{CFI}=.916, \mathrm{RMSEA}=.060(.056, .065), \mathrm{SRMR}=.077$. The metric model did not significantly deteriorate, $\chi^{2}=563.35, \mathrm{p}<.001, \mathrm{CFI}=.928, \mathrm{RMSEA}=$ $.049(.046, .054), \mathrm{SRMR}=.081$. The scalar model also did not deteriorate, $\chi^{2}=587.83$, $\mathrm{p}<.001, \mathrm{CFI}=.924, \mathrm{RMSEA}=.052(.048, .056), \mathrm{SRMR}=.079$. The scalar model with residuals constrained also did not significantly deteriorate, $\chi^{2}=587.83, \mathrm{p}<.001, \mathrm{CFI}=$ $.924, \mathrm{RMSEA}=.052(.048, .056), \mathrm{SRMR}=.079$. The results revealed there was invariance at the strict level for MDE across racial groups, see table 6.

MG CFA - Income Level

There were 1,594 less than $\$ 20,000$, there were 2,329 in the $\$ 20,000-\$ 49,999$ category, 1,186 participants in \$50,000-\$74,999 category, and 2,535 participants in $\$ 75,000$ or more categories used in the model due to missing data. The configural model showed adequate fit, $\chi^{2}=654.31, \mathrm{p}<.001, \mathrm{CFI}=.910, \mathrm{RMSEA}=.062(.058, .066)$, $\mathrm{SRMR}=.079$. The metric model did not significantly deteriorate, $\chi^{2}=614.25, \mathrm{p}<.001$, $\mathrm{CFI}=.919, \mathrm{RMSEA}=.052(.048, .056), \mathrm{SRMR}=.082$. The scalar model also did not deteriorate, $\chi^{2}=637.75, \mathrm{p}<.001, \mathrm{CFI}=.915, \mathrm{RMSEA}=.054(.050, .058), \mathrm{SRMR}=.081$. The scalar model with residuals constrained also did not significantly deteriorate, $\chi^{2}=$ $637.75, \mathrm{p}<.001, \mathrm{CFI}=.915, \mathrm{RMSEA}=.054(.050, .058), \mathrm{SRMR}=.081$. The results revealed there was invariance at the strict level for MDE among all income levels, see table 7 .

MG CFA - Education Level

There were 687 people who had less than a high school diploma, there were 1,647 high school graduates, 3,081 people who had some college or an associate degree and were 2,229 college graduates used in the model due to missing data. The configural 
model showed adequate fit, $\chi^{2}=650.94, \mathrm{p}<.001, \mathrm{CFI}=.909, \mathrm{RMSEA}=.062(.057, .066)$, $\mathrm{SRMR}=.079$. The metric model did not significantly deteriorate, $\chi^{2}=614.98, \mathrm{p}<.001$, $\mathrm{CFI}=.918, \mathrm{RMSEA}=.052(.048, .056), \mathrm{SRMR}=.083$. The scalar model also did not deteriorate, $\chi^{2}=646.48, \mathrm{p}<.001, \mathrm{CFI}=.913, \mathrm{RMSEA}=.055(.051, .059), \mathrm{SRMR}=.082$. The scalar model with residuals constrained also did not significantly deteriorate, $\chi^{2}=$ 646.48, $\mathrm{p}<.001, \mathrm{CFI}=.913, \mathrm{RMSEA}=.055(.051, .059), \mathrm{SRMR}=.082$. The results revealed there was invariance at the strict level for MDE among all education levels, see table 8 .

Reliability/ Validity

Alpha coefficient for the overall MDE module was .605.

\section{Discussion}

This study aimed to fill a gap in research by examining the factor structure of the MDE module used in the NSDUH, which is administered across the United States. The structure of the MDE module was examined first followed invariance tests between different sociodemographics. This was done to determine if the MDE module was comparable across groups. Specially, gender, race, income level, and education levels were tested. It was found that the factor structure of the MDE module was a 1-factor solution. This indicates that all items were measuring on one construct, depression. One item did need to be dropped in order to increase fit, however the study moved forward with the 8-item model. As expected, all remaining items were related to each other. The item that was removed from the model was general feelings of sadness. The 1-factor model held up when used on a different sample of the NSDUH. 
The MDE module used in the NSDUH was found to be a 1-factor model after removing one item from the module. This 1-factor model held consistent when tested by sex, race/ethnicity, income level, and education level. Invariance testing proceeded using the 1-factor, 8-item model.

Invariance was tested across gender, race, income level, and education level. It was found that each demographic had strict equivalence across all groups. This means that the MDE module measured the same construct and is comparable between males and females, White, Black, Hispanic/Latinx, and all other races/ethnicities, income levels, and education levels. With strict equivalence on this measure, future studies can feel confident in comparing MDE across gender, race, and SES.

Overall, the model held up through all the demographics. This supports the use of the MDE module regardless of gender, race/ethnicity, income level, or education level. The MDE should measure lifetime depression symptoms throughout each of these groups. The use of the MDE module in the NSDUH is supported by this finding, as it is a national level survey and measuring the same structure is important. The consistency in models between gender, race/ ethnicity, income, and education is positive when thinking about the NSDUH reaching the general population of the United States. Using a module that holds true for many different demographics is important when trying to get an accurate measure of depression in a random sample nationwide.

There are limitations to this data. The overall model fit was not ideal. This could be due to the nature of the module or due to the nature of the sample. Further studies should aim to validate the MDE module on different samples. The data was collected cross-sectionally in a nationwide study. While this allows for a representative sample of 
our country, it also restricts the scales that can be used and the ability to track participants over time. Further validation would benefit from the MDE module being studied longitudinally, although given the fact that the NSDUH itself is an annual survey that does not connect participants to past surveys there would be no way to study this longitudinally. While the sample is representative of the United States, another inherit limitation with the NSDUH is that people who are active-duty armed forces are not allowed to participate. The MDE module itself did not have the best reliability, as there are other scales that measure depression more reliably, it is a downside of using a set national dataset.

Given the limitations of the current study, the results are still impactful. Having knowledge that the MDE module is invariant across various demographics allows for comparison between these groups in future work. Moving forward researchers can feel confident that results using the MDE module will be meaningful regardless of sex, race, or SES. 


\section{References}

Alegria, M., Chatterji, P., Wells, K., Cao, Z., Chen, C., Takeuchi, D., Jackson, J., \& Meng, X. (2008). Disparity in depression treatment among racial and ethnic minority populations in the United States. Psychiatric Services, 59(11), 12641272. DOI:10.1176/appi.ps.59.11.1264.

American Psychiatric Association (2000). Diagnostic and statistical manual of mental disorders (4th ed., Text Revision).

American Psychiatric Association. (2013). Diagnostic and statistical manual of mental disorders (5th ed.). https://doi.org/10.1176/appi.books.9780890425596.

Bailey, R. K., Mokonogho, J., Kumar, A. (2019). Racial and ethnic differences in depression: current perspectives. Neuropsychiatric Disease and Treatment, 15, 603-609. https://doi.org/10.2147/NDT.S128584.

Barbara M. Byrne, Pierre Baron \& T. Leanne Campbell (1993) Measuring Adolescent Depression: Factorial Validity and Invariance of the Beck Depression Inventory Across Gender, Journal of Research on Adolescence, 3(2), 127143, https://doi.org/10.1207/s15327795jira0302 2

Borges, G., Angst, J., Nock, M. K., Ruscio, A. M., Walters, E. E., \& Kessler, R. C. (2006). Risk factors for twelve-month suicide attempts in the national comorbidity survey replication (NCS-R). Psychology Medicine, 36(12), 17471757. DOI: 
Bromet, E., Andrade, L. H., Hwang, I., Sampson, N. A., Alonso, J., Girolamo, G. d., Graaf, R. d., Demyttenaere, K., Hu, C., Iwata, N., Karam, A. N., et al. (2011). Cross-national epidemiology of DSM-IV major depressive episode. Bio Medicine Central, 9:90. http://www.biomedcentral.com/1741-7015/9/90.

Cattell, R. B. (1966). The scree test for the number of factors. Multivariate Behavioral Research, 1(2), 245-276. https://doi.org/10.1207/s15327906mbr0102_10.

Eduardo Fonseca-Pedrero, Craig Wells, Mercedes Paino, Serafín Lemos-Giráldez, Úrsula Villazón-García, Susana Sierra, Ma Paz García-Portilla González, Julio Bobes \& José Muñiz (2010) Measurement Invariance of the Reynolds Depression Adolescent Scale across Gender and Age, International Journal of Testing, 10:2, 133-148, https://doi.org/10.1080/15305050903580822.

Escobar, K. M., \& Gorey, K., M. (2018). Cognitive behavioral interventions for depression among Hispanic people: promising meta-analytic evidence for deep cultural adaptations. Social Work in Mental Health, 16(6), 746-758. DOI:10.1080/15332985.2018.1476284.

Fava, M., Hwang, I., Rush, A.J., Sampson, N., Walters, E.E., \& Kessler, R. (2010). The importance of irritability as a symptom of major depressive disorder: results from the national comorbidity survey replication. Molecular Psychiatry, 15, 856-867.

Friedrich, M. J. (2017). Depression is the leading cause of disability around the world. Global Health, 317(15), 1517. DOI:10.1001/jama.2017.3826. 
GBD 2017 Disease and Injury Incidence and Prevalence Collaborators. (2018).

Global, regional, and national incidence, prevalence, and years lived with disability for 354 diseases and injuries for 195 countries and territories, 19902017: a systematic analysis for the Global Burden of Disease Study 2017. The Lancet. https://doi.org/10.1016/S0140-6736(18)32279-7.

Feldman, L. A. (1993). Distinguishing depression and anxiety in self-report: Evidence from confirmatory factor analysis on nonclinical and clinical samples. Journal of Consulting and Clinical Psychology, 61(4), 631638. https://doi.org/10.1037/0022-006X.61.4.631.

Goodman, E., \& Huang, B. (2002). Socioeconomic status, depressive symptoms, and adolescent substance use. Archive Pediatric Adolescent Medicine, 150.

Hankerson, S. H., Fenton, M. C., Geier, T. J., Keyes, K. M., Weissman, M. M., \& Hasin, D. S. (2011). Racial differences in symptoms, comorbidity, and treatment for major depressive disorder among black and white adults. Journal of National Medical Association, 103(7), 576-584. https://doi.org/10.1016/S0027-9684(15)30383-7.

Hedden, S., Gfroerer, J., Barker, P., Smith, S., Pemberton, M. R., Saavedra, L. M., Forman-Hoffman, V. L., Ringeisen, \& Noval, S. P. (2012). Comparison of NSDUH mental health data and methods with other data sources. Center for Behavioral Health Statistics and Quality. https://www.ncbi.nlm.nih.gov/books/NBK390286/. 
Hu, L.T., \& Bentler, P. M. (1999). Cutoff criteria for fit indexes in covariance structure analysis: Conventional criteria versus new alternative. Structural Equation Modeling: A Multidisciplinary Journal, 6(1), 1-55.

Inaba, A., Thoits, P. A., Ueno, K., Gove, W. R., Evenson, R. J., \& Sloan, M. (2005). Depression in the United States and Japan: Gender, marital, status, and SES patterns. Social Science \& Medicine, 6, 2280-2292.

DOI:10.1016/j.socscimed.2005.07.014.

Karg, R. S., Bose, J., Batts, K. R., Forman-Hoffman, V. L., Liao, D., Hirsch, E., Pemberton, M. R., Colpe, L. J., \& Hedden, S.L. (2014). Past year mental disorders among adults in the United States: Results from the 2008-2012 mental health surveillance study. Center for Behavioral Health Statistics and Quality.

Kessler, R. C., Birnbaum, H., Bromet, E., Hwang, I., Sampson, N., \& Shahly, V. (2010). Age differences in major depression: Results from the national comorbidity surveys replication (NCS-R). Psychology Medicine, 40(2), 225243. DOI: $10.1017 / \mathrm{S} 0033291709990213$.

Kessler, R.C., Berglund, P., Demler, O., Jin, R., Koretz, D., Merikangas, K. R., Rush, A. J., Walters, E. E., \& Wang, P.S. (2003). The epidemiology of major depressive disorder results from the national comorbidity survey replication (NCS-R). JAMA, 289(23), 3095-3105.

Kessler, R.C., Berglund. P., Chiu, W. T., Demler, O., Heeringa, E. H., Jin, R., Pennell, B., Walters, E. E., Zaslavsky, A., \& Zheng, H. (2006). The US 
national comorbidity survey replication (NCS-R): design and field procedures. International Journal of Methods in Psychiatric Research, 13 (2), 69-92. https://doi.org/10.1002/mpr.167.

Kessler, R. C., Gruber, M., Hettema, J.M., Hwang, I., Sampson, BA., Yonkers, K. A. (2008). Comorbid major depression and generalized anxiety disorders in the national comorbidity survey follow-up. Psychology Medicine, 38(3), 365-374. DOI:10.1017/S00033291707002012.

Kuehner, C. (2003) Gender differences in unipolar depression: an update of epidemiological findings and possible explanations. Acta Psychiatrica Scandinavica, 108(3). https://doi.org/10.1034/j.1600-0447.2003.00204.x.

Lu, Q., He, H., Yang, J., Feng, X., Zhao, F., Lyu, J. (2020). Changes in the global burden of depression from 1990 to 2017: Findings from the global burden of disease study. Journal of Psychiatric Research, 126, 134-140. https://doi.org/10.1016/i.jpsychires.2019.08.002.

Major depression. (2019, February). Retrieved February 17, 2021, from https://www.nimh.nih.gov/health/statistics/majordepression.shtml\#part_155029.

Pemberton, M., R., Bose, J., Kilmer, G., Kroutil, L.A., Forman-Hoffman, V.L., \& Gfroerer, J. C. (2013). Comparison of NSDUH health and health care estimates to other national data sources. Center for Behavioral Health Statistics and Quality. 
RStudio Team (2020). RStudio: Integrated Development for R. RStudio, PBC, Boston, MA URL http://www.rstudio.com/.

Ryan, T.A., Bailey, A., Fearon, P. and King, J. (2013), Factorial invariance of the Patient Health Questionnaire and Generalized Anxiety Disorder Questionnaire. Br J Clin Psychol, 52: 438-

449. https://doi.org/10.1111/bjc.12028.

Substance Abuse and Mental Health Services Administration. (2012). Mental Health, United States, 2010. HHS Publication No. (SMA) 12-4681. Rockville, MD: Substance Abuse and Mental Health Services Administration.

U.S. Department of Health and Human Services, Substance Abuse and Mental Health Services Administration, Center for Behavioral Health Statistics and Quality. (2019). National Survey on Drug Use and Health 2018 (NSDUH-2018DS0001). Retrieved from https://datafiles.samhsa.gov/. 
Tables

Table 1.

Frequencies for Sociodemographics $(\mathrm{N}=7,644)$

\begin{tabular}{|l|l|l|}
\hline & Frequency & Percent \\
\hline Gender (Sex) & & \\
\hline Male & 2,778 & $36.30 \%$ \\
\hline Female & 4,866 & $63.70 \%$ \\
\hline Race & & \\
\hline Non-Hispanic White & 5,274 & $69 \%$ \\
\hline Non-Hispanic Black/ African American & 643 & $8.40 \%$ \\
\hline Hispanic & 1,037 & $13.60 \%$ \\
\hline All Other Races & 690 & $9 \%$ \\
\hline Family Income Level & & \\
\hline Less than \$20,000 & 1,594 & $20.90 \%$ \\
\hline \$20,000 - \$49,999 & 2,329 & $30.50 \%$ \\
\hline \$50,000 - \$74,999 & 1,186 & $15.50 \%$ \\
\hline More than \$75,000 & 2,535 & $33.20 \%$ \\
\hline Education Level & & \\
\hline Less than high school & 687 & $9.00 \%$ \\
\hline High school graduate & 1,647 & $21.50 \%$ \\
\hline Some College/ Associate Degree & 3,081 & $40.30 \%$ \\
\hline College graduate & 2,229 & $29.20 \%$ \\
\hline
\end{tabular}


Table 2.

Correlation table with 8 -items

\begin{tabular}{|c|c|c|c|c|c|c|c|c|}
\hline \multicolumn{9}{|c|}{ CFA Correlation Table } \\
\hline & $\begin{array}{l}\text { MDE } \\
\text { Item } 2\end{array}$ & $\begin{array}{l}\text { MDE } \\
\text { Item } 3\end{array}$ & $\begin{array}{l}\text { MDE } \\
\text { Item } 4\end{array}$ & $\begin{array}{l}\text { MDE } \\
\text { Item } 5\end{array}$ & $\begin{array}{l}\text { MDE } \\
\text { Item } 6\end{array}$ & $\begin{array}{l}\text { MDE } \\
\text { Item } 7\end{array}$ & $\begin{array}{l}\text { MDE } \\
\text { Item } 8\end{array}$ & $\begin{array}{l}\text { MDE } \\
\text { Item } 9\end{array}$ \\
\hline $\begin{array}{l}\text { MDE } \\
\text { Item } 2\end{array}$ & -- & & & & & & & \\
\hline $\begin{array}{l}\mathrm{MDE} \\
\text { Item } 3\end{array}$ & $.173 *$ & -- & & & & & & \\
\hline $\begin{array}{l}\text { MDE } \\
\text { Item } 4\end{array}$ & $.176^{*}$ & $.229 *$ & -- & & & & & \\
\hline $\begin{array}{l}\text { MDE } \\
\text { Item } 5\end{array}$ & $.135^{*}$ & $.196^{*}$ & $.136^{*}$ & -- & & & & \\
\hline $\begin{array}{l}\text { MDE } \\
\text { Item } 6\end{array}$ & $.168 *$ & $.129 *$ & $.343^{*}$ & $.149 *$ & -- & & & \\
\hline $\begin{array}{l}\text { MDE } \\
\text { Item } 7\end{array}$ & $.209 *$ & $.154 *$ & $.123 *$ & $.200 *$ & $.166^{*}$ & -- & & \\
\hline $\begin{array}{l}\text { MDE } \\
\text { Item } 8\end{array}$ & $.177^{*}$ & $.173^{*}$ & $.197^{*}$ & $.272 *$ & $.220 *$ & $.241 *$ & -- & \\
\hline $\begin{array}{l}\text { MDE } \\
\text { Item } 9\end{array}$ & $.171^{*}$ & $.099 *$ & $.102 *$ & $.102 *$ & $.108^{*}$ & $.346^{*}$ & $.142 *$ & -- \\
\hline
\end{tabular}

Table 3.

Major Depressive Episode Scale 1-Factor standardized loadings

\begin{tabular}{|l|r|}
\hline \multicolumn{2}{|c|}{ CFA Standardized Factor Loadings } \\
\hline MDE item 2 & 0.663 \\
\hline MDE item 3 & 0.750 \\
\hline MDE item 4 & 0.589 \\
\hline MDE item 5 & 0.702 \\
\hline MDE item 6 & 0.519 \\
\hline MDE item 7 & 0.559 \\
\hline MDE item 8 & 0.547 \\
\hline MDE item 9 & 0.751 \\
\hline
\end{tabular}


Table 4.

Invariance Test results for Gender

\begin{tabular}{|l|l|l|l|l|l|}
\hline Model & $\chi^{2}, \mathrm{p}$ & $d f$ & CFI & $\begin{array}{l}\text { RMSEA } \\
{[90 \% \mathrm{CI}]}\end{array}$ & SRMR \\
\hline 1 Factor Model - Gender & & & & & \\
\hline Configural & $\begin{array}{l}605.88, \mathrm{p} \\
<.001\end{array}$ & 40 & 0.912 & $\begin{array}{l}0.062[.057, \\
.066]\end{array}$ & 0.077 \\
\hline Metric & $587.74, \mathrm{p}<.001$ & 47 & 0.916 & $.055[.052, .060]$ & 0.078 \\
\hline Scalar & $645.04, \mathrm{p}<.001$ & 46 & 0.907 & $.059[.055, .063]$ & 0.079 \\
\hline Strict & $654.04, \mathrm{p}<.001$ & 46 & 0.907 & $.059[.055, .063]$ & 0.079 \\
\hline
\end{tabular}

Table 5.

Invariance Test results for Race

\begin{tabular}{|l|l|l|l|l|l|}
\hline Model & $\chi^{2}, \mathrm{p}$ & $d f$ & CFI & $\begin{array}{l}\text { RMSEA } \\
{[90 \% \mathrm{CI}]}\end{array}$ & SRMR \\
\hline $\begin{array}{l}\text { 1 Factor Model - } \\
\text { Race/Ethnicity }\end{array}$ & & & & & \\
\hline Configural & $620.09, \mathrm{p}<.001$ & 80 & 0.916 & $.060[.056, .065]$ & 0.077 \\
\hline Metric & $563.35, \mathrm{p}<.001$ & $\begin{array}{l}10 \\
1\end{array}$ & 0.928 & $.049[.046, .054]$ & 0.081 \\
\hline Scalar & $587.83, \mathrm{p}<.001$ & 98 & 0.924 & $.052[.048, .056]$ & 0.079 \\
\hline Strict & $587.83, \mathrm{p}<.001$ & 98 & 0.924 & $.052[.048, .056]$ & 0.079 \\
\hline
\end{tabular}

Table 6.

Invariance Test results for Income

\begin{tabular}{|l|l|l|l|l|l|}
\hline Model & $\chi^{2}, \mathrm{p}$ & $d f$ & CFI & RMSEA [90\%CI] & SRMR \\
\hline 1 Factor Model - Income & & & & & \\
\hline Configural & $654.31, \mathrm{p}<.001$ & 80 & 0.91 & $.062[.058, .066]$ & 0.079 \\
\hline Metric & $614.25, \mathrm{p}<.001$ & 101 & 0.919 & $.052[.048, .056]$ & 0.082 \\
\hline Scalar & $637.75, \mathrm{p}<.001$ & 98 & 0.915 & $.054[.050, .058]$ & 0.081 \\
\hline Strict & $637.75, \mathrm{p}<.002$ & 98 & 0.915 & $.054[.050, .058]$ & 0.081 \\
\hline
\end{tabular}


Table 7.

Invariance Test results for Education

\begin{tabular}{|l|l|l|l|l|l|}
\hline Model & $\chi^{2}, \mathrm{p}$ & $d f$ & CFI & $\begin{array}{l}\text { RMSEA } \\
{[90 \% \mathrm{CI}]}\end{array}$ & SRMR \\
\hline $\begin{array}{l}1 \text { Factor Model - } \\
\text { Education }\end{array}$ & & & & & \\
\hline Configural & $650.94, \mathrm{p}<.001$ & 80 & 0.909 & $\begin{array}{l}.062[.057, \\
.066]\end{array}$ & 0.079 \\
\hline Metric & $614.98, \mathrm{p}<.001$ & $\begin{array}{l}10 \\
1\end{array}$ & 0.918 & $\begin{array}{l}.052[.048, \\
.056]\end{array}$ & 0.083 \\
\hline Scalar & $646.48, \mathrm{p}<.001$ & 98 & 0.913 & $\begin{array}{l}.055[.051, \\
.059]\end{array}$ & 0.082 \\
\hline Strict & $646.48, \mathrm{p}<.002$ & 98 & 0.913 & $\begin{array}{l}.055[.051, \\
.059]\end{array}$ & 0.082 \\
\hline
\end{tabular}




\section{MANUSCRIPT -2 \\ In preparation for Journal of Cross-Cultural Psychology}

Co-occurance of Depressive Symptoms and Alcohol Use: The Impact of Sociodemographic Factors

Marie Tate, Andrea Paiva, Lynda Stein, and Bryan Blissmer

Psychology, University of Rhode Island, Kingston, RI

Kinesiology, University of Rhode Island, Kingston, RI

Corresponding Author: Marie Tate, Ph.D.

Psychology Department

University of Rhode Island

142 Flagg Rd

Kingston, RI 02881

Phone: 540-604-7021

Email address: marie tate15@uri.edu 


\begin{abstract}
The comorbidity of depression and alcohol use has been common in our society for many years (Floud et al., 2015). The purpose of the current study is to investigate the role that race, gender, and socioeconomic status have on the comorbidity between depression and alcohol use. This study was using a national dataset, the National Survey of Drug Use and Health. The results indicated that sociodemographics did not change the relationship between depression and alcohol use. However, there were differences between depression symptoms and alcohol use on the socioeconomic demographics. This indicates that sociodemographics do play a role in both depression symptoms and alcohol use, even though they do not change the relationship. The implications of this study are two-fold, it sets up future research to be done people who may not have depression but screen into a depression scale to determine how these factors effect depression and alcohol use and it indicates research using national data sets is feasible and important.
\end{abstract}


Co-occurrence of Depressive Symptoms and Alcohol Use: The Impact of Sociodemographic Factors

Depression and alcohol use have commonly co-occurred in our society for many years (Flouds et al., 2015; Gierisch et al., 2011). The direction of the relationship between depression and alcohol use has not been consistent in research (Peirce et al., 2000; Conner et al., 2008; Sullivan et al., 2005) and the role of sociodemographic variables (e.g., gender, race, and socioeconomic status (SES)) have not been thoroughly investigated. Large national data sets exist that can be leveraged to study this relationship (e.g. National Survey on Drug Use and Health; Treatment Episode Data Set). The purpose of the current study is to investigate how different sociodemographic variables (e.g., gender, race, SES) can change the relationship between depressive symptoms and alcohol use. This will be done using a national dataset that is collected annually and funded by the Substance Abuse and Mental Health Administration (SAMHSA).

The co-occurrence of alcohol use and depression has been a prevalent issue in our society for many years (Foulds et al., 2015; Gierisch et al., 2011; Holahan et al., 2003; Swendsen et al., 2000). Past research (Peirce et al., 2000; Sullivan et al., 2005) has attempted to explain the directionality of the relationship between depression and alcohol use in multiple ways. Many researchers (Peirce et al., 2000; Conner et al., 2008) have found, people with depression utilize alcohol as a method to cope with negative affect and it can create a cyclical cycle with the relationship between depression and alcohol use. Due to the nature of the relationship, selecting which one should be the focal outcome variable has varied based on the sample type. The current study will follow the Lee et al. (2013) study, which used alcohol as the outcome variable since their study 
focused on people who were not required to be currently diagnosed with depression. Since co-occurrence of depression and alcohol use prevalent in the United States, it is important to study multiple factors that could change the relationship between the two.

Past research has studied the impact that various sociodemographic factors have on the co-occurrence between depression and alcohol use, including race, gender, and SES. However, most studies have limited the number of factors included in their sample and model. Lee et al. (2013) is one of the few that accounted for multiple factors and found that education level plays a significant role in the relationship between mental health and substance abuse symptoms when considering gender, race, and other health factors, within a community sample. It was found that people who did not have a high school diploma prior to 21 were more likely to have comorbidity of mental health issues, including depression, and substance use issues later in life (Lee et al., 2013). While race and gender were included as covariates, they were not the focal point of Lee et al. (2013) results.

When the past research (Salas et al., 2015) has investigated the co-occurrence between depression and alcohol use with race as the primary variable, it was found that White people were more likely to have co-occurrence than Black/ African Americans. Compton et al. (2010) found similar results, African American people were not more likely to have comorbidity disorders than White people. Other studies (Garlow, 2002) have found that ethanol was more likely to be in the system of White people who had committed suicide than any other race. While the co-occurrence does appear more frequently in the White samples, literature finds that the co-occurrence in African American's is linked to worse outcomes (Dagher \& Green, 2014). These outcomes 
include, low educational attainment, poor work outcomes, high unemployment levels, and welfare dependency (Dagher \& Green, 2014). This heightens the importance of accounting for multiple sociodemographic factors within one model.

Other studies have investigated the role that gender plays in the relationship between depressive symptoms and substance use (Wilkinson et al., 2016; Poikolainen et al., 2001; Rohde et al., 2001). Through the various research methods implemented, the overall findings seem to consistently find that the co-occurrence between depression and alcohol use is stronger in women (Poulin et al. 2004; Sordo et al., 2012). Poikolainen et al. (2001) found that depression symptoms are linked to later drinking behavior, after accounting for gender. Multiple studies have also supported that women are at greater risk of having depressive symptoms than men (Rohde et al., 2001; Kuehner, 2003) however, overall men are at greater risk of substance use disorders (Rohde et al., 2001). This increases the importance of studying how gender can change the relationship between depression/ depressive symptoms and alcohol use. When investigating the impact of gender as a moderator in a longitudinal study, Moscato et al. (1997) found that depressive symptoms predicted alcohol problems among females, over a three-year period, there was no significance in predicting alcohol problems in males.

When the relationship between depression and substance use has been studied focusing on SES primary covariate (Karriker-Jaffe, 2013; Sunder et al., 2007; Tormohlen et al., 2019), SES is not measured in the same way. For example, income level, education level, and parents' education level have all been used as measures of SES. While there are various ways to measure SES, many studies include only one factor to capture SES (Gelea et al., 2007; Sunder et al., 2007; Tormohlen et al., 2019). Galea et al. (2007) only 
used income levels to measure SES. They used Gini scores to measure the SES of the overall neighborhoods that participants lived in (Galea et al., 2007). They found that as neighborhood Gini scores increased (or median income level became higher) alcohol use increased (Galea et al., 2007). Humensky (2010) investigated the relationship between SES status and substance use. He defined SES status as income and education level of parents. Families with higher household income level were more likely to engage in binge drinking and marijuana use, although these were small findings (Humensky, 2010). It was also found that people with college educated parents were more likely to engage in binge drinking, use marijuana, and cocaine versus people who had high school educated parents (Humensky, 2010). Dagher and Green (2014) found that young adults with longer periods of unemployment had a higher chance of having substance use issues and/or depressive symptoms. This result indicates that it might not be the SES a person is in but what actions they are taking in life (Dagher \& Green, 2014). Goodman and Huang (2002) found that in adolescents, that lower SES, measured by education level of a parent and income level, was negatively related to cigarette smoking but positively related to alcohol consumption. Adolescents who lived in higher income houses, consumed more alcohol (Goodman \& Huang, 2002).

Other studies investigated the relationship between drug use and depression within one level of SES. Tormohlen et al. (2019) investigated the relationship between co-occurring drug use and depression symptoms. Using 336 adults from Baltimore City who had co-occurring depressive symptoms and drug use, multiple stressors are related to the co-occurrence (Tormohlen et al., 2019). However, for our purpose of looking at this study, it was found that drug-related financial stress was related to increase substance 
use. Disordered problems within the neighborhood was related to increased drug use. Other factors were related, however, those did not involve money or neighborhood environment (Tormohlen et al., 2019). Research on the co-occurrence between depression and substance use with SES as a predictor or moderating third variable was not very strong within the literature.

While many past studies have investigated the impact of race, gender, and SES not many have studied them together. The few studies which included multiple sociodemographic factors found that taken into account together does affect the relationship. Assari (2018) found that when race and SES were in one model, there was a higher risk of depression among African Americans which is contradictory to Mezuck et al. (2010) finding that depression was more common in White people. Tormohlen et al. (2019) found that when gender is included in a study the impact of SES is not as strong. This supports the need to incorporate multiple sociodemographic variables into one study even more.

The current study will investigate how gender, race, and SES can influence the relationship between depressive symptoms and alcohol use for people who screen into taking a depression measure. Using a national dataset, National Survey on Drug Use and Health (NSDUH), we will gain knowledge on how the co-occurrence of depressive symptoms and alcohol use can change across the nation. It also provides insights on how to utilize a national dataset that is collected annually in a way that can predict health behaviors. Not only will this study provide insight on the relationship between depressive symptoms and alcohol use it will expand the abilities of the utilization of national datasets that use federal funds to collect. 


\section{Method}

National Survey on Drug Use and Health (NSDUH)

The data for the current study will come from the NSDUH (SAMHSA, 2019), which is used to track specific substance use, mental health problems, treatments, and other health-related information. Data are collected annually using an independent, multistage area probability sample within each of the 50 states and the District of Columbia. People are excluded from the study if they are active military employees. There are no requirements for having used substances or experienced mental health issues. The NSDUH collects data from people 12 and older, however due to differences in the depression questionnaire, the current study will use data from only participants 18 and older. The survey is administered via an audio computer-assisted self-interviewing system (Hedden et al., 2012). For a more detailed description of how data was collected view the "Results from the 2018 National Survey on Drug Use and Mental Health: Summary of National Findings" (SAMHSA, 2019).

\section{Sample}

The current study will use a sample of all participants 18 and older from the 2018 NSDUH (SAMHSA, 2019). There are 7,644 participants who screened into taking the depression scale. There were 4,866 (63.7\%) females and 2,778 (36.3\%) males. Participants were mostly non-Hispanic White $(5,274 ; 69 \%)$, Hispanic $(1,037 ; 13.6 \%)$ and non-Hispanic Black/African American (643; 8.4\%), there were 690 (9\%) in all other races. See table 1 for demographics.

Measures

Major Depressive Episodes 
Major Depressive Episodes (MDE) module is based on the fourth edition of the Diagnostic and Statistical Manual of Mental Disorders (DSM-IV) (American Psychiatric Association (APA), 2000). In order to measure depression in adults, the NSDUH uses an adapted version of the National Comorbidity Survey - Revised (NCS-R) (Kessler et al., 2005). Revisions were made to reduce the length. For the current study, we will use the endorsement of major depressive symptoms during the lifetime, all participants answered yes to a series of questions in order to be screened into taking the major depressive episode (MDE) module. If they said no to, "Have you ever in your life had a period of time lasting several days or longer when most of the day you felt sad, empty or depressed?"; "Have you ever had a period of time lasting several days or longer when most of the day you were very discouraged about how things were going in your life?"; or "Have you ever had a period of time lasting several days or longer when you lost interest in most of the things you usually enjoy like work, hobbies, and personal relationships?" they were not screened into taking the depression scale. The scale was investigated in a previous study and found a 1-factor, 8 -item structure, that will be used in the current study. There are eight questions asked in the lifetime MDE module. If a participant responded yes to five out of the nine symptoms than they fell into the category of having a MDE in their lifetime. For the current study, we will not classify people as yes or no for MDE in lifetime, instead we will create a sum score (0-8) in order to measure number of depressive symptoms in the lifetime per participant (SAMHSA, 2019).

Alcohol Use 
Alcohol use per month is measured by a composite variable of amount of alcohol the participant has consumed in the past 30 days and number of drinks consumed on days drinking. The question asked was "What is your best estimate of the number of days you drank alcohol during the past 30 days?" There were nine options for past 30 days drinking, (1) 1 or 2 days, (2) 3 to 5 days, (3) 6 to 9 days, (4) 10 to 19 days, (5) 20 to 29 days, (6) all 30 days, (7) never used alcohol, (8) did not use alcohol in the past 30 days, and (9) don't know (SAMHSA, 2019). The number of drinks that you drank on the days you drank ranged from 1 to 90 . These two were multiplied to get the approximate number of drinks in past 30 days.

We also wanted to measure high-risk drinking. In order to do this, we will be using a binge drinking measure. Participants were asked "During the past 30 days, that is since ___, on how many days did you have $[4$ or more $] /[5$ or more $]$ drinks on the same occasion? By "occasion," we mean at the same time or within a couple of hours of each other." Participants could report anywhere from 0 to 30 days.

\section{Sociodemographics}

The NSDUH recategorizes gender into sex, (1) male and (2) female (SAMHSA, 2019). Sex will be the measure used in the current study.

The measure for race/ ethnicity consists of (1) non-Hispanic White, (2) nonHispanic Black/ African American, (3) non-Hispanic Native American/ Alaskan Native, (4) non-Hispanic Native Hawaiian/ Other Pacific Islander, (5) non-Hispanic Asian, (6)

non-Hispanic more than one race, and (7) Hispanic (SAMHSA, 2019). The current study found that non-Hispanic White, Hispanic, and Black/ African American were the only 
racial categories that took up more than $5 \%$ of the data, therefore non-Hispanic Native American/ Alaskan Native, non-Hispanic Native Hawaiian/ Other Pacific Islander, nonHispanic Asian, and non-Hispanic more than one race were all grouped together to be defined as all other races.

SES will be comprised of two separate variables, education level and income level. Education categories included (1) less high school, (2) high school graduate, (3) some college/ associate degree, and (4) college graduate (SAMHSA, 2019). Income level was measures by total annual family income and the options were (1) less than $\$ 10,000$, (2) $\$ 10,000-\$ 19,999$, , (3) $\$ 20,000-\$ 29,999$, (4) $\$ 30,000-\$ 39,999,(5) \$ 40,000-\$ 49,999$, (6) $\$ 50,000-\$ 74,999$, (7) $\$ 75,000$ or more (SAMHSA, 2019).

\section{Proposed Analysis}

In order to determine the effect of the sociodemographic variables on the relationship between depression and alcohol use in the last month, four moderation analyses will be conducted. The Hayes (2013) PROCESS package will be used in order to investigate this relationship. Cohen's technique (1988) for effect sizes will be used to measure the effect for t-tests and eta-squared $\left(\omega^{2}\right)$ will be used to measure effect size for analysis of variance (ANOVA). Each factor will be used as a focal moderator and the other three factors will be included in the moderation model as covariates. Using the regression model allows for multiple categories to be accounted for within each moderating variable. With regression moderation, the interaction between the IV and the moderating variable will first be investigated, if significant, than probing will be done on the interaction to determine where the change in the relationship between the IV and the DV exists, each significant change will then be reported. Next, we will run four 
moderation analyses to test if depressive symptoms and high-risk alcohol use is affected by the sociodemographic factors. Again, each moderation analysis will include one focal moderator with the remaining variables as covariates. This method will allow us take into account multiple sociodemographic factors at once.

\section{Results}

\section{Descriptive and Correlations}

All variables were tested for normality, the number of alcoholic beverages consumed in a month was the only variable not found to be normally distributed (see table 2). There were 35,336 removed for either responding to less than 2 items on the 8item MDE module. There were 46 outliers removed, all outliers were 3 standard deviations above the mean for number of alcoholic beverages consumed in one month. Once the outliers were removed, the number of alcoholic beverages consumed in a month was normally distributed. The adjusted MDE module with eight items was correlated to both the number of binge drinking days in a month and the number of alcoholic beverages consumed, and gender, race, income levels, and education level (see table 3). Since number of alcoholic beverages was not correlated to the MDE module and wouldn't be used for the remainder of analyses, the 46 outliers were put back into the dataset, normality was tested again (see table 4), and correlations were rerun without the number of alcoholic beverages consumed variable (see table 5). Since number of binge drinking episodes was correlated with the MDE module, $r(4,686)=-.039, \mathrm{p}=.008$, gender, $r(4,686)=-.081, \mathrm{p}<.001$, family income $r(4,686)=-.074, \mathrm{p}<.001$, and education level, $r(4,686)=-.081, \mathrm{p}<.001$. Race however, was not related to binge drinking, $r(4,686)=-$ $.024, p=.101$. 


\section{Regression}

A bivariate regression with the adjusted MDE module as the predictor and binge drinking as the dependent variable was found the be significant, $F(1,4686)=7.151$, $\mathrm{p}=.008$, with an $\mathrm{R}^{2}=.002$. As the MDE scale increased by one unit, reported binge drinking decreased by .039 .

Moderation Analyses

A moderation analysis using PROCESS in SPSS v 25 was done with the adjusted MDE module as the independent variable, binge drinking as the dependent variable, and gender as the moderator. Family income, education level, and race were included as covariates. It was found that the model had an overall significant, $F(6,4681)=13.900$, $\mathrm{p}<.001$, with an $\mathrm{R}^{2}=.132$. The adjusted MDE module was not significant, $\beta=-.044$, $\mathrm{p}=.761$. Gender was significantly related to binge drinking, $\beta=-.724, p=.001$. Gender did not significantly moderate the relationship between the adjusted MDE module and binge drinking, $\beta=-.033, p=.707$. The other demographics were significant covariates, race $(\beta=$ $-.174, \mathrm{p}=.012)$, family income $(\beta=-.250, \mathrm{p}<.001)$, and education level $(\beta=-.318, \mathrm{p}<.001)$. See table 6 for all moderation results.

Another moderation analysis using PROCESS in SPSS v 25 was done with the adjusted MDE module as the independent variable, binge drinking as the dependent variable, this time using race as the moderator. Family income, education level, and gender were included as covariates. It was found that the model had an overall significant, $F(6,4681)=13.949, \mathrm{p}<.001$, with an $\mathrm{R}^{2}=.133$. The adjusted MDE module was not significant, $\beta=-.051, p=.534$. Race was not significantly related to binge 
drinking, $\beta=-.123, p=.240$. Race did not significantly moderate the relationship between the adjusted MDE module and binge drinking, $\beta=-.028, p=.513$. The other demographics were significant covariates, gender $(\beta=-.784, \mathrm{p}<.001)$, family income $(\beta=-.251, \mathrm{p}<.001)$, and education level $(\beta=-.319, \mathrm{p}<.001)$.

A third moderation analysis using PROCESS in SPSS v 25 was done with the adjusted MDE module as the independent variable, binge drinking as the dependent variable, using family income level as a moderator. Education level, gender, and race were included as covariates. It was found that the model had an overall significant, $F(6$, $4681)=14.023, \mathrm{p}<.001$, with an $\mathrm{R}^{2}=.133$. The adjusted MDE module was not significant, $\beta=.002, p=.987$. Family income was significantly related to binge drinking, $\beta=-.186, p=.049$. Family income did not significantly moderate the relationship between the adjusted MDE module and binge drinking, $\beta=-.035, p=.353$. The other demographics were significant covariates, gender $(\beta=-.788, p<.001)$, education level $(\beta=-.318$, $\mathrm{p}<.001)$, and race $(\beta=-.177, \mathrm{p}=.011)$.

The last moderation analysis using PROCESS in SPSS v25 was done with the adjusted MDE module as the independent variable, binge drinking as the dependent variable, education level as the moderator. Family income level, gender, and race were included as covariates. It was found that the model had an overall significant, $F(6$, $4681)=13.88, \mathrm{p}<.001$, with an $\mathrm{R}^{2}=.132$. The adjusted MDE module was not significant, $\beta=-.066, p=.669$. Education level was significantly related to binge drinking, $\beta=-.301$, $\mathrm{p}=.014$. Education level did not significantly moderate the relationship between the adjusted MDE module and binge drinking, $\beta=-.010, p=.837$. The other demographics 
were significant covariates, gender $(\beta=-.787, p<.001)$, family income $(\beta=-.250, p<.001)$, and $\operatorname{race}(\beta=-.175, \mathrm{p}=.012)$.

Since none of the sociodemographic variables significantly moderated the relationship between the adjusted MDE scale and binge drinking the interaction was removed and all variables were used as covariates in a linear regression. The overall model was significant, $F(5,4682)=16.66, \mathrm{p}<.001$, with an $\mathrm{R}^{2}=.132$. The adjusted MDE module was significant, $\beta=-.032 p=.028$. Gender was significantly related to binge drinking, $\beta=-.080, p<.001$. Education level was significantly related to binge drinking, $\beta=-.059, p<.001$. Family income level was significantly related to binge drinking, $\beta=-$ $.060, \mathrm{p}<.001$. Race was significantly related to binge drinking, $\beta=-.037, p=.012$. Mean Comparison on adjusted MDE and Binge Drinking

Since all sociodemographic variables were significantly related to binge drinking but did not moderate the relationship between the adjust MDE module and binge drinking, mean comparison testing was done. First mean comparisons were done to investigate differences on the adjusted MDE scale. A t-test was conducted to determine if differences in adjusted MDE scores occurred between males $(M=1.98, S D=1.71)$ and females $(M=1.74, S D=1.51)$, there was a significance, $\mathrm{t}(7,642)=5.989, \mathrm{p}<.001(95 \% \mathrm{CI}$ : $.157, .310)$, Cohen's $d=.15$. An effect size of .15 indicates a small to medium effect. An ANOVA investigating the differences in the adjusted MDE module and racial groups was not significant, $F(3,7640)=1.860, \mathrm{p}=.134$. See table 7 .

An ANOVA found significant differences between education levels and the adjusted MDE score, $F(3,7640)=42.306, \mathrm{p}<.001, \omega^{2}=.02$ An $\omega^{2}$ of .02 indicates a small 
effect. Post Hoc Tukey tests found significant differences between less than high school $(M=1.62, S D=1.60)$ and college graduate $(M=2.14, S D=1.63)$, high school graduate $(M=$ $1.64, S D=1.55)$ and college graduate, and some college/ associate degree $(M=1.75$, $S D=1.55$ ) and college graduate. People with less than a high school degree, high school degrees, and some college/ associate degree reported less MDE symptoms than college graduates.

Another ANOVA found significant differences in the adjusted MDE module between family income levels, $F(3,7640)=25.609, \mathrm{p}<.001, \omega^{2}=.01$. Even though there are significant differences an $\omega^{2}$ of .01 indicates a small effect. There were significant differences between families making less than $\$ 20,000(M=1.60, S D=1.53)$ and those making $\$ 20,000$ - $\$ 49,999(M=1.75, S D=1.55)$, less than $\$ 20,000$ and $\$ 50,000-\$ 74,999$ $(M=1.84, S D=1.60)$, less than $\$ 20,000$ and more than $\$ 75,000(M=2.02, S D=1.63)$, $\$ 20,000$ - $\$ 49,999$ and more than $\$ 75,000$, and $\$ 50,000-\$ 74,999$ and more than $\$ 75,000$. Those in families making less than $\$ 75,000$ annually reported less MDE symptoms than families who made more than $\$ 75,000$.

Lastly, one t-test and three ANOVAs were conducted to investigate group differences for binge drinking episodes in a month. A t-test was conducted to determine if differences in number days a person binge drank in one month occurred between males $(M=2.92, S D=5.51)$ and females $(M=2.16, S D=4.26)$, there was a significance, $\mathrm{t}(2,968.79)=4.978, \mathrm{p}<.001(95 \%$ CI: .463, 1.065), $d=.16$. A Cohen's $d$ of .16 indicates a small to medium effect. An ANOVA investigating the differences in the number of binge drinking episodes in a month and racial groups was not significant, $F(3,4684)=1.717$, $\mathrm{p}=.16$. See table 8 . 
An ANOVA found significant differences between education levels and binge drinking episodes, $F(3,4684)=42.306, \mathrm{p}<.001, \omega^{2}=.01$. An omega squared of .01 indicates that the overall effect was small even though there are significant differences. Post Hoc Tukey tests found significant differences between less than high school $(M=$ 3.27, $S D=6.03)$ and some college/ associates degree $(M=2.44, S D=4.73)$, less than high school and college graduate $(M=2.03, S D=4.14)$, high school graduate $(M=2.95$, $S D=5.40)$ and some college/ associate degree $(M=2.44, S D=4.73)$, high school graduate and college graduate, some college/ associate degree and college graduate. People with less than a high school degree had significant more binge drinking episodes in one month than all other groups. College graduates had significantly less binge drinking episodes in one month than all other groups.

Another ANOVA found significant differences in the binge drinking and family income levels, $F(3,4684)=8.768, \mathrm{p}<.001, \omega^{2}=.01$. An omega squared of .01 indicates that the overall effect was small even though there are significant differences. There were significant differences between families making less than $\$ 20,000(M=3.041, S D=5.290)$ and those $\$ 50,000-\$ 74,999(M=2.331, S D=4.464)$, less than $\$ 20,000$ and more than $\$ 75,000(M=2.066, S D=4.339)$, and $\$ 20,000-\$ 49,999(M=2.593, S D=5.060)$ and more than $\$ 75,000$. Those in families making less than $\$ 20,000$ annually reported more binge drinking episodes than families who made between $\$ 50,000$ and $\$ 74,999$ and $\$ 75,000$.

\section{Discussion}

The purpose of the current study was to investigate the relationship between depression symptoms and alcohol use, and how sociodemographics can influence this relationship. The relationship between lifetime depression symptoms and past month 
alcoholic consumption were not related. This was a surprising finding given past literature supports the relationship between depression and alcohol use (Peirce et al., 2000; Sullivan et al., 2005). However, the lack of significance between depression symptoms and alcohol consumption could be due to the fact that our participants had to screen into taking the MDE module and it measured lifetime depression. Therefore, they did not currently have to be experiencing depression symptoms during the month that they are reported binge drinking. However, when investigating the relationship between depression symptoms and binge drinking there was a relationship though. Once the sociodemographic variables were included in a moderation analysis, depression symptoms were no longer related to binge drinking episodes in a month. The sociodemographic variables did not moderate this relationship, but they were significantly related to depression symptoms and binge drinking episodes in a month.

To further the analysis, I investigated how binge drinking episodes and depression symptoms differed by gender, income level, and education level within the sample that screened into the depression module. Neither binge drinking nor depression symptoms differed by race. There were differences in all other sociodemographics for both depression symptoms and binge drinking episodes. Males reported more lifetime depression symptoms and more binge drinking episodes in one month than females. This contradicts past research (Rohde et al., 2001; Kuehner, 2003) as it is commonly found that females experience more depressive symptoms than males. However, this could be due to the fact that a higher proportion of males did not screen into taking the depression module, the overall percentage of males in the NSDUH was $46 \%$ and the percentage of males that screened in took up 36\%. It is important to note that for males who did screen 
into the depression module, both number of depression symptoms and number of binge drinking episode reported in a month was higher. This could indicate that when males are flagged for depression, they could report more depression symptoms than females and this could impact prevention work. Further investigation would be valuable to determine if this finding is consistent within other samples.

When investigating education levels further, the current findings provide support that the number binge drinking episodes in one month are more common among people with less education. People who screened into the depression module and had less than high school education reported more binge drinking episodes than those with some college and college degrees. People with high school degrees binge drank more in one month than those with some college and college degrees. People with some college binge drank more in one month than those with college degrees. Those with the college degrees binge drank less in a month than all other education levels, reporting binge drinking 2.02 days in one month on average. However, the reverse was found for depression symptoms in a lifetime. Those who screened into the depression scale and had a college degrees reported more lifetime depression symptoms than any other group. College graduates reported on average 2.14 lifetime depression symptoms out of the eight symptoms measured.

A similar pattern was found when investigating binge drinking and depression between income levels. Participants who were part of families that made less than $\$ 20,000$ annually binge drank more than those who made $\$ 50,000-\$ 75,000$ and more than $\$ 75,000$ annually. Reporting 3 binge drinking episodes a month on average. People who were part of families making $\$ 20,000$ to $\$ 49,999$ annually binge drank more than 
those making more than $\$ 75,000$. People with lower income levels (less than $\$ 20,000$ ) reported significantly less lifetime depression symptoms than all other income levels. Participants who were in families that made between $\$ 20,000-\$ 49,999$ reported less symptoms than people who were part of families that made more than $\$ 75,000$ annually. People who were part of families that made more than $\$ 75,000$ annually reported more depression symptoms than all other groups, reporting 2.02 depression symptoms.

These findings demonstrate that there are differences in drinking behaviors and reporting depression symptoms across different sociodemographics. However, more research is needed in order to determine what is influencing these different relationships in this population. Continued research could help tailor depression and/or alcohol use treatment to better fit the needs of different demographics and prevention work. One reason drinking levels could be lower among the college graduate sample could be an indication of the work that colleges and universities do to prevent substance use and dependency among their students. This finding could be useful for the public health field and targeting prevention work towards people who did not finish high school or those who didn't attend college. Targeting people in low income is showing to be a continued concern that public health officials should strategize programs and outreach plans to reach.

The findings also indicate that depression symptoms are reported more frequently reported in participants who have graduated college or are in high income brackets. This finding could be due to the fact that these symptoms were reported throughout a person's lifetime and not their current feelings, which indicate that a person with a college degree is more likely to have depression in their lifetime. It would not necessarily mean in the 
current time they are more likely to experience these symptoms. This finding could be used to remind college students about mental health resources, work on reducing mental illness stigma and encourage self-care.

As with all research, there are limitations. Within this study we used a national survey to conduct the analysis. This makes it difficult to use best practice scales to measure depression symptoms. It also encourages more skip patterns, which increases missing data for analyses. The data is also not longitudinal, so cross-sectional analysis was necessary within this dataset.

That being said, using a national sample has many benefits. It was representative of the United States and we were able to study depression and alcohol use within a nationwide sample of people 18 and older who screened into a depression module. Moving forward including different mental/ behavioral health variables in the analysis might give us a better image as to what influences the relationship between depression and alcohol use. Incorporating other substances used, age of first use, and past treatment might change the outcomes of the current findings. All these variables are available in the NSDUH and could be valuable in targeting treatment and prevention moving forward.

\section{Conclusion}

The relationship between depression and alcohol use seems to be very complex. Sociodemographics influence both depression symptoms and alcohol use however they do not change the relationship between depression and alcohol use, although they do reduce the relationship between depression and alcohol use when included as moderators. Since the interactions are not significant though, depression and binge drinking is still 
related with race, gender, income, and education level are included as covariates.

Findings suggest that depression symptoms are higher among college graduates and people who are part of families making more than $\$ 75,000$ annually. While binge drinking is higher among people who have not graduated college and make less than $\$ 20,000$ annually. These findings indicate the treatment and prevention for alcohol use should be targeted towards people who have not graduated college or live in low SES. In the field of public health, these are already populations that are being targeted. It might be useful to increase mental health awareness and reduce stigma in people who have graduated college or make more than $\$ 75,000$ as they reported more depressive symptoms. 


\section{References}

American Psychiatric Association (2000). Diagnostic and statistical manual of mental disorders (4th ed., Text Revision).

Assari, S., Mistry, R., Caldwell, C. H., \& Zimmerman, M. A. (2018). Marijuana use and depressive symptoms; Gender differences in African American adolescents. Frontiers in Psychology, 9. DOI:10.3389/fpsyg.2018.02135.

Cattell, R. B. (1966). The scree test for the number of factors. Multivariate Behavioral Research, 1(2), 245-276.

https://doi.org/10.1207/s15327906mbr0102_10.

Cohen, J. (1988). Statistical power analysis for the behavioral sciences $\left(2^{\text {nd }} \mathrm{ed}\right.$.). Hillside, N.J.: Lawrence Erlbaum Associates.

Conner, K. R., Pinquart, M., \& Halbrook, A. P. (2008). Meta-analysis of depression and substance use and impairment among cocaine users. Drug and Alcohol Dependence, 98. DOI:10.1016/j.drugalcdep.2008.05.005.

Compton III, W. M., Cottler, L. B., Abdallah, A. B., Phelps, D. L., Spitznagel, E. L., \& Hotron, J. C. (2010). Substance dependence and other psychiatric disorders among drug dependent subjects: race and gender correlates. The American Journal on Addictions, 9 (2). https://doi.org/10.1080/10550490050173181.

Dagher, R. K., \& Green, K. M. (2015). Does depression and substance abuse comorbidity affect socioeconomic status? Evidence from a prospective study of urban African Americans. Psychiatry Research, 225(0).

DOI:10.1016/j.psychres.2014.10.026. 
Foulds, J. A., Adamson, S. J., Boden, J. M., Williman, J. A., \& Mulder, R. T. (2015). Depression in patients with alcohol use disorders: Systematic review and meta-analysis of outcomes for independent and substance-induced disorders. Journal of Affective Disorders, 185(1). https://doi.org/10.1016/j.jad.2015.06.024.

Galea, S., Ahern, J., Tracy, M., \& Vlahov, D. (2007). Neighborhood income and income distribution and the use of cigarette, alcohol, and marijuana. American Journal of Preventative Medicine, 32.

Garlow, S. J. (2002). Age, gender, and ethnicity differences in patterns of cocaine and ethanol use preceding suicide. American Journal of Psychiatry, 159.

Gierisch, J. M., Bastian, L. A., Calhoun, P. S., McDuffie, J. R., \& Williams, J. W. (2011). Smoking cessation interventions for patients with depression: A systematic review and meta-analysis. Journal of General Internal Medicine, 27(3). https://doi.org/10.1007/s11606-011-1915-2.

Goodman, E., \& Huang, B. (2002). Socioeconomic status, depressive symptoms, and adolescent substance use. Archive Pediatric Adolescent Medicine, 150.

Gorka, S. M., Ali, B., \& Daughters, S. B. (2012). The role of distress tolerance in the relationship between depressive symptoms and problematic alcohol use. Psychology of Addictive Behavior, 26(3), 621-626. Doi:10.1037/a0026386.

Green, K. M., \& Stuart, E. A. (2014). Examining moderation analyses in propensity score methods: Application to depression and substance use. Journal of Consulting Clinical Psychology, 82(5). DOI:10.1037/a0036515. 
Hayes, A. F., (2013). Introduction to mediation, moderation, and conditional process analysis: A regression-based approach. New York, NY: The Guilford Press.

Hedden, S., Gfroerer, J., Barker, P., Smith, S. (2012). Comparison of NSDUH mental health data and methods with other data sources. Center for Behavioral Health Statistics and Quality Data Review.

Holahan, C. J., Moos, R. H., Holahan, C. K., Cronkite, R. C., \& Randall, P. K. (2003). Drinking to cope and alcohol use and abuse in unipolar depression: A 10-year model. Journal of Abnormal Psychology,112(1), 159-165.

DOI:10.1037/0021-843X.112.1.159.

Hu, L.T., \& Bentler, P. M. (1999). Cutoff criteria for fit indexes in covariance structure analysis: Conventional criteria versus new alternative. Structural Equation Modeling: A Multidisciplinary Journal, 6(1), 1-55.

Humensky, J. L. (2010). Are adolescents with high socioeconomic status more likely to engage in alcohol and illicit drug use in early adulthood? Substance Abuse Treatment, Prevention, and Policy, 5(19).

Karriker-Jaffe, K. J. (2013) Neighborhood socioeconomic status and substance use by U.S. adults. Drug Alcohol Dependency, 133(1), 212-221.

DOI:10.1016/j/drugalcdep/2013.04.033.

Kessler, R.C., Chiu, W.T., Demler, O., Merikangas, K. R., Walters, E.E. (2005).

Prevalence, severity, and comorbidity of twelve-month DSM-IV disorders in the National Comorbidity Survey Replication (NCS-R). Archives of General Psychiatry, 62(6), 617-627. 
Kuehner, C. (2003) Gender differences in unipolar depression: an update of epidemiological findings and possible explanations. Acta Psychiatrica Scandinavica, 108(3). https://doi.org/10.1034/j.1600-0447.2003.00204.x.

Lee, J. O., Herrenkohl, T. L., Kostermann, R., Small, C. M., \& Hawkins, D. (2013). Educational inequalities in the co-occurrence of mental health and substance use problems, and its adult socioeconomic consequences: A longitudinal study of adults in a community sample. Public Health, 127(8).

DOI:10.1016/j.puhe.2013.04.005.

Mezuk, B., Raffrety, J. A., Kershaw, K. N., Hudson, D., Abdou, C. M., Lee, H., Eaton, W. W., \& Jackson, J. S. (2010). Reconsidering the role of social disadvantage in physical and mental health: Stressful life events, health behaviors, race, and depression. American Journal of Epidemiology, 172(11), 1238-1249. DOI:10.1093/aje/kwq283.

Mojtabai, R., Chen, L., Kaufmann, C. N., \& Crum, R. M. (2014). Comparing barriers to mental health treatment and substance use disorder treatment among individuals with comorbid major depression and substance use disorder. Journal of Substance Abuse Treatment, 46. http://dx.doi.org/10.1016/j.jsat.2013.07.012.

Marmorstein, N. R. (2009). Longitudinal associations between alcohol problems and depressive symptoms: Early adolescence through early adulthood. Alcoholism: Clinical and Experimental Research, 33(1). DOI:10.1111/j.15300277.2008.00810.x. 
Moscato, B. S., Russell, M., Zielezny, M., Bromet, E., Egri, G., Mudar, P., \& Marshall, J. R. (1997). Gender differences in the relation between depressive symptoms and alcohol problems: A longitudinal perspective. American Journal of Epidemiology, 146(11).

Peirce, R. S., Frone, M. R., Russell, M., Cooper, M. L., \& Mudar, P. (2000). A longitudinal model of social contact, social support, depression, and alcohol use. Health Psychology, 19(1), 28-38. DOI: 10.1037//0278-6133.19.1.28.

Poikolainen, K., Tuulio-Henriksson, A., Aalto-Setälä,T., Marttunen, M., Lönnqvist, J. (2001) Predictors of alcohol intake and heavy drinking in early adulthood: a 5year follow-up of 15-19-year-old Finnish adolescents, Alcohol and Alcoholism, 36(1), 85-88, https://doi.org/10.1093/alcalc/36.1.85

Poulin, C., Hand, D., Boudreau, B., \& Santor, D. (2004). Gender differences in the association between substance use and elevated depressive symptoms in a general adolescent population. Addiction, 100. DOI:10.1111/j.13600443.2005.01033.x.

Rohde, P., Lewinsohn, P. M., Kahler, C. W., Seeley, J. R., \& Brown, R. A. (2001). Natural course of alcohol use disorders from adolescence to young adulthood. Journal of the American Academy of Child \& Adolescent Psychiatry, 40(1), 83-90. https://doi.org/10.1097/00004583-200101000-00020.

RStudio Team (2020). RStudio: Integrated Development for R. RStudio, PBC, Boston, MA URL http://www.rstudio.com/. 
Salas, J., Scherrer, J. F., Lustman, P. J., \& Schneider, F. D. (2016). Racial differences in the association between nonmedical prescription opioid use, abuse/ dependence, and major depression. Substance Abuse Journal, 37(1). DOI:10.1080/08897077.2015.1129523.

Sullivan, L. E., Fiellin, D. A., \& O’Connor, P. G. (2005). The prevalence and impact of alcohol problems in major depression: A systematic review. The American Journal of Medicine, 118. DOI:10.1016/j.amjmed.2005.01.007.

Sordo, L., Chahua, M., Barvo, M. J., Barrio, G., Brugal, M. T., Domingo-Salvany, A., Molist, G., Fuente, L. D., \& ITINERE Project Group (2012). Depression among regular heroin users: The influence of gender. Addictive Behaviors, 37. DOI:10.1016/j.addbeh.2011.09.009.

Swendsen, J. D., \& Merikangas (2000). The comorbidity of depression and substance use disorder. Clinical Psychology Review, 20(2).

Tormohlen, K. N., Tobin, K. E., \& Latkin, C. (2019). Sources of stress among adults with co-occurring drug use and depressive symptoms. Journal of Urban Health, 96(3). https://doi.org/10.1007/s11524-018-0304-0.

U.S. Department of Health and Human Services, Substance Abuse and Mental Health Services Administration, Center for Behavioral Health Statistics and Quality. (2019). National Survey on Drug Use and Health 2018 (NSDUH-2018DS0001). Retrieved from https://datafiles.samhsa.gov/

Wilkinson, A. L., Halpern, C. T., Herring, A. H., Shanahan, M., Ennett, S. T., Hussey, J. M., \& Harris, K. M. (2016). Testing longitudinal relationships 
between binge drinking, marijuana use, and depressive symptoms and moderation by sex. Journal of Adolescent Health, 59.

http://dx.doi.org/10.1016/j.jadhealth.2016.07.010. 
Tables.

Table 1.

Frequencies for Sociodemographics w/o Alcohol Consumption $(\mathrm{N}=7,644)$

\begin{tabular}{|l|l|l|}
\hline & Frequency & Percent \\
\hline Gender (Sex) & & \\
\hline Male & 2,778 & $36.30 \%$ \\
\hline Female & 4,866 & $63.70 \%$ \\
\hline Race & & \\
\hline Non-Hispanic White & 5,274 & $69 \%$ \\
\hline Non-Hispanic Black/ African American & 643 & $8.40 \%$ \\
\hline Hispanic & 1,037 & $13.60 \%$ \\
\hline All Other Races & 690 & $9 \%$ \\
\hline Family Income Level & & \\
\hline Less than \$20,000 & 1,594 & $20.90 \%$ \\
\hline \$20,000 - \$49,999 & 2,329 & $30.50 \%$ \\
\hline$\$ 50,000$ - \$74,999 & 1,186 & $15.50 \%$ \\
\hline More than \$75,000 & 2,535 & $33.20 \%$ \\
\hline Education Level & & \\
\hline Less than high school & 687 & $9.00 \%$ \\
\hline High school graduate & 1,647 & $21.50 \%$ \\
\hline Some College/ Associate Degree & 3,081 & $40.30 \%$ \\
\hline College graduate & 2,229 & $29.20 \%$ \\
\hline
\end{tabular}

Table 2.

Descriptive Statistics

\begin{tabular}{|l|l|l|l|l|l|}
\hline & $\mathrm{N}$ & Mean & Standard Deviation & Skewness & Kurtosis \\
\hline Adjusted MDE & $\begin{array}{l}7,59 \\
8\end{array}$ & 1.829 & 1.588 & 0.887 & 0.416 \\
\hline Binge Drinking Episodes & $\begin{array}{l}4,64 \\
2\end{array}$ & 2.265 & 4.330 & 3.661 & 16.286 \\
\hline Alcohol Consumption & $\begin{array}{l}4,41 \\
4\end{array}$ & 22.291 & 30.078 & 2.792 & 9.623 \\
\hline
\end{tabular}


Table 3.

Correlation Table with alcohol consumption

\begin{tabular}{|l|l|l|l|l|l|l|l|}
\hline & $\begin{array}{l}\text { Adjuste } \\
\mathrm{d} \text { MDE }\end{array}$ & $\begin{array}{l}\text { Alcohol } \\
\text { Consumptio } \\
\mathrm{n}\end{array}$ & $\begin{array}{l}\text { Binge } \\
\text { Drinking } \\
\text { Episodes }\end{array}$ & Race & $\begin{array}{l}\text { Gende } \\
\mathrm{r}\end{array}$ & $\begin{array}{l}\text { Incom } \\
\mathrm{e}\end{array}$ & $\begin{array}{l}\text { Educatio } \\
\mathrm{n}\end{array}$ \\
\hline Adjusted MDE & -- & & & & & & \\
\hline $\begin{array}{l}\text { Alcohol } \\
\text { Consumption }\end{array}$ & -0.011 & -- & & & & & \\
\hline $\begin{array}{l}\text { Binge } \\
\text { Drinking } \\
\text { Episodes }\end{array}$ & $-.038^{*}$ & $.803^{*}$ & -- & & & & \\
\hline Race & -0.014 & $-.038^{*}$ & -.021 & -- & & & \\
\hline Gender & $-.072^{*}$ & $-.153^{*}$ & -.053 & 0.002 & -- & & \\
\hline Income & $.100^{*}$ & $-.053^{*}$ & $-.060^{*}$ & $-.111^{*}$ & -.045 & -- & \\
\hline Education & $.114^{*}$ & $-.053^{*}$ & $-.060^{*}$ & $-.104^{*}$ & $.040^{*}$ & $.323^{*}$ & -- \\
\hline
\end{tabular}

Table 4.

Descriptive statistics without Alcohol Consumption

\begin{tabular}{|l|l|l|l|l|l|}
\hline & $\mathrm{N}$ & Mean & Standard Deviation & Skewness & Kurtosis \\
\hline Adjusted MDE & $\begin{array}{l}7,64 \\
4\end{array}$ & 1.828 & 1.588 & 0.886 & 0.409 \\
\hline Binge Drinking Episodes & $\begin{array}{l}4,68 \\
8\end{array}$ & 2.443 & 4.330 & 3.598 & 14.942 \\
\hline
\end{tabular}


Table 5.

Correlation Table without alcohol consumption

\begin{tabular}{|l|l|l|l|l|l|l|}
\hline & $\begin{array}{l}\text { Adjusted } \\
\text { MDE }\end{array}$ & $\begin{array}{l}\text { Binge } \\
\text { Drinking } \\
\text { Episodes }\end{array}$ & Race & Gender & Income & Education \\
\hline Adjusted MDE & -- & & & & & \\
\hline $\begin{array}{l}\text { Binge Drinking } \\
\text { Episodes }\end{array}$ & $-.039^{*}$ & -- & & & & \\
\hline Race & -0.014 & -.024 & -- & & & \\
\hline Gender & $-.071^{*}$ & $-.077^{*}$ & 0.001 & -- & & \\
\hline Income & $.100^{*}$ & $-.074^{*}$ & $-.110^{*}$ & $-.044^{*}$ & -- & \\
\hline Education & $.114^{*}$ & $-.081^{*}$ & $-.104^{*}$ & $.042^{*}$ & $.324^{*}$ & -- \\
\hline
\end{tabular}


Table 6.

Moderation between depression and binge drinking with $\mathrm{X}$ as the focal moderator

\begin{tabular}{|c|c|c|c|c|c|}
\hline Model summary & $\mathrm{R}^{2}$ & $F$ & $\begin{array}{l}\text { Degree of } \\
\text { Freedom } 1\end{array}$ & $\begin{array}{l}\text { Degrees of } \\
\text { Freedom } 2\end{array}$ & $\mathrm{P}$ \\
\hline MDE*Race & 0.018 & 13.95 & 6 & 4681 & $<.001$ \\
\hline MDE*Gender $^{*}$ & 0.018 & 13.9 & 6 & 4681 & $<.001$ \\
\hline MDE*Income & 0.018 & 14.02 & 6 & 4681 & $<.001$ \\
\hline $\begin{array}{l}\text { MDE*Educatio } \\
n\end{array}$ & 0.018 & 13.88 & 6 & 4681 & $<.001$ \\
\hline Model & $\begin{array}{l}\text { Estimat } \\
\mathrm{e}\end{array}$ & $\begin{array}{l}\text { Std. } \\
\text { error }\end{array}$ & $t$ & $\mathrm{p}$ & $\begin{array}{l}95 \% \text { CI (LCI, } \\
\text { UCI) }\end{array}$ \\
\hline Intercept & 5.74 & 0.41 & 14.18 & $<.001$ & $(4.95,6.54)$ \\
\hline MDE & -0.05 & 0.08 & -0.62 & 0.53 & $(-.21, .11)$ \\
\hline Race & -0.12 & 0.11 & -1.18 & 0.24 & $(-.33, .08)$ \\
\hline MDE*Race & -0.03 & 0.04 & -0.65 & 0.51 & $(-.11, .06)$ \\
\hline Gender & -0.78 & 0.14 & -5.45 & $<.001$ & $(-1.07,-.50)$ \\
\hline Income & -0.25 & 0.06 & -3.92 & $<.001$ & $(-.38,-.13)$ \\
\hline Education & -0.32 & 0.08 & -3.8 & $<.001$ & $(-.48,-.15)$ \\
\hline Intercept & 5.72 & 0.47 & 12.06 & $<.001$ & $(4.79,6.65)$ \\
\hline MDE & -0.04 & 0.14 & -0.3 & 0.76 & $(-.33, .24)$ \\
\hline Gender & -0.72 & 0.22 & -3.27 & 0.001 & $(-1.16,-.29)$ \\
\hline MDE*Gender $^{*}$ & -0.03 & 0.09 & -0.38 & 0.71 & $(-.20, .14)$ \\
\hline Race & -0.17 & 0.07 & -2.5 & 0.01 & $(-.31,-.04)$ \\
\hline Income & -0.25 & 0.06 & -3.91 & $<.001$ & $(-.38,-.12)$ \\
\hline Education & -0.32 & 0.08 & -3.79 & $<.001$ & $(-.48,-.15)$ \\
\hline Intercept & 5.66 & 0.43 & 13.28 & $<.001$ & $(4.82,6.49)$ \\
\hline MDE & 0.002 & 0.11 & 0.02 & 0.99 & $(-.22, .22)$ \\
\hline Income & -0.19 & 0.09 & -1.97 & 0.05 & $(-.37,-.00)$ \\
\hline MDE*Income & -0.04 &.-4 & -0.93 & 0.35 & $(-.11, .04)$ \\
\hline Race & -0.18 & 0.07 & -2.54 & 0.01 & $(-1.07,-.51)$ \\
\hline Gender & -0.79 & 0.14 & -5.48 & $<.001$ & $(-1.07,-.51)$ \\
\hline Education & -0.32 & 0.08 & -3.79 & $<.001$ & $(-.48,-.15)$ \\
\hline Intercept & 5.77 & 0.47 & 12.33 & $<.001$ & $(4.86,6.69)$ \\
\hline MDE & -0.07 & 0.15 & -0.43 & 0.67 & $(-.37, .23)$ \\
\hline Education & -0.3 & 0.12 & -2.47 & 0.01 & $(-.54,-.06)$ \\
\hline $\begin{array}{l}\text { MDE*Educatio } \\
\mathrm{n}\end{array}$ & -0.01 & 0.05 & -0.21 & 0.84 & $(-.10, .08)$ \\
\hline Race & -0.18 & 0.07 & -2.51 & 0.01 & $(-.31,-.04)$ \\
\hline Gender & -0.79 & 0.14 & -5.46 & $<.001$ & $(-1.07,-.50)$ \\
\hline Income & -0.25 & 0.06 & -3.9 & $<.001$ & $(-.3757,-.12)$ \\
\hline
\end{tabular}


Table 7.

ANOVAs and T-test with depression as the outcome variable

\begin{tabular}{|c|c|c|c|c|c|}
\hline \multicolumn{6}{|l|}{ Depression } \\
\hline Variable & $N$ & Mean & SD & $\mathrm{P}$ value & Effect Size \\
\hline \multicolumn{6}{|l|}{ Gender } \\
\hline Male & $\begin{array}{l}277 \\
8 \\
\end{array}$ & 1.98 & $\begin{array}{l}1.7 \\
1 \\
\end{array}$ & $<.001$ & $d=.15$ \\
\hline Female & $\begin{array}{l}486 \\
6 \\
\end{array}$ & 1.74 & $\begin{array}{l}1.5 \\
1\end{array}$ & & \\
\hline \multicolumn{6}{|l|}{ Race } \\
\hline Non-Hispanic White & $\begin{array}{l}527 \\
4\end{array}$ & 1.84 & $\begin{array}{l}1.6 \\
0\end{array}$ & 0.134 & -- \\
\hline Hispanic & $\begin{array}{l}103 \\
7\end{array}$ & 1.73 & $\begin{array}{l}1.5 \\
4\end{array}$ & & \\
\hline Non-Hispanic Black/African American & 643 & 1.90 & $\begin{array}{l}1.6 \\
1\end{array}$ & & \\
\hline All other races & 690 & 1.82 & $\begin{array}{l}1.5 \\
8 \\
\end{array}$ & & \\
\hline \multicolumn{6}{|l|}{ Education Level } \\
\hline Less than High School & 687 & 1.62 & 1.6 & $<.001$ & $\omega^{2}=0.02$ \\
\hline High School Diploma & $\begin{array}{l}164 \\
7\end{array}$ & 1.64 & $\begin{array}{l}1.5 \\
5\end{array}$ & & \\
\hline Some college/ Associates Degree & $\begin{array}{l}308 \\
1\end{array}$ & 1.75 & $\begin{array}{l}1.5 \\
5 \\
\end{array}$ & & \\
\hline College Graduate & $\begin{array}{l}222 \\
9\end{array}$ & 2.14 & $\begin{array}{l}1.6 \\
3\end{array}$ & & \\
\hline \multicolumn{6}{|l|}{ Income Level } \\
\hline Less than $\$ 20,000$ & $\begin{array}{l}159 \\
4\end{array}$ & 1.6 & $\begin{array}{l}1.5 \\
3\end{array}$ & $<.001$ & $\omega^{2}=0.01$ \\
\hline$\$ 20,000-\$ 49,999$ & $\begin{array}{l}232 \\
9\end{array}$ & 1.75 & $\begin{array}{l}1.5 \\
5\end{array}$ & & \\
\hline$\$ 50,000-\$ 74,999$ & $\begin{array}{l}118 \\
6\end{array}$ & 1.86 & 1.6 & & \\
\hline More than $\$ 75,000$ & $\begin{array}{l}253 \\
5\end{array}$ & 2.02 & $\begin{array}{l}1.6 \\
3\end{array}$ & & \\
\hline
\end{tabular}


Table 8 .

ANOVAs and T-tests with Binge Drinking as the outcome variable

\begin{tabular}{|l|l|l|l|l|l|}
\hline Binge Drinking & $N$ & Mean & SD & P value & Effect Size \\
\hline Variable & & & & & \\
\hline Gender & 174 & 2.92 & 5.5 & $<.001$ & $d=.16$ \\
\hline Male & 2 & & 1 & & \\
\hline Female & 294 & 2.16 & 4.2 & & \\
& 6 & & 6 & & \\
\hline Race & & & & & \\
\hline Non-Hispanic White & 328 & 2.54 & 5.0 & 0.16 & -- \\
& 8 & & 5 & & \\
\hline Hispanic & 606 & 2.32 & 4.1 & & \\
& & & 4 & & \\
\hline Non-Hispanic Black/African American & 395 & 2.04 & 3.8 & & \\
& & & 6 & & \\
\hline All other races & 399 & 2.25 & 4.0 & & \\
& & & 9 & & \\
\hline Education Level & & & & & \\
\hline Less than High School & 286 & 3.27 & 6.0 & $<.001$ & $\omega^{2}=0.01$ \\
& & & 3 & & \\
\hline High School Diploma & 858 & 2.95 & 5.4 & & \\
\hline Some college/ Associates Degree & 193 & 2.44 & 4.7 & & \\
& 2 & & 3 & \\
\hline College Graduate & 161 & 2.03 & 4.1 & & \\
& 2 & & 4 & & \\
\hline Income Level & & & & & \\
\hline Less than \$20,000 & 875 & 3.04 & 5.2 & $<.001$ \\
\hline \$20,000 - \$49,999 & 136 & 2.59 & 5.0 & & \\
\hline \$50,000 - \$74,999 & 0 & & 6 & & \\
\hline More than \$75,000 & 741 & 2.33 & 4.4 & & \\
& 2 & 2.07 & 4.3 & & \\
\hline & & & & & \\
\hline
\end{tabular}




\section{Bibliography}

Alegria, M., Chatterji, P., Wells, K., Cao, Z., Chen, C., Takeuchi, D., Jackson, J., \& Meng, X. (2008). Disparity in depression treatment among racial and ethnic minority populations in the United States. Psychiatric Services, 59(11), 12641272. DOI:10.1176/appi.ps.59.11.1264.

American Psychiatric Association (2000). Diagnostic and statistical manual of mental disorders (4th ed., Text Revision).

American Psychiatric Association. (2013). Diagnostic and statistical manual of mental disorders (5th ed.). https://doi.org/10.1176/appi.books.9780890425596.

Assari, S., Mistry, R., Caldwell, C. H., \& Zimmerman, M. A. (2018). Marijuana use and depressive symptoms; Gender differences in African American adolescents. Frontiers in Psychology, 9. DOI:10.3389/fpsyg.2018.02135.

Bailey, R. K., Mokonogho, J., Kumar, A. (2019). Racial and ethnic differences in depression: current perspectives. Neuropsychiatric Disease and Treatment, 15, 603-609. https://doi.org/10.2147/NDT.S128584.

Barbara M. Byrne, Pierre Baron \& T. Leanne Campbell (1993) Measuring Adolescent Depression: Factorial Validity and Invariance of the Beck Depression Inventory Across Gender, Journal of Research on Adolescence, 3(2), 127143, https://doi.org/10.1207/s15327795jra0302_2

Borges, G., Angst, J., Nock, M. K., Ruscio, A. M., Walters, E. E., \& Kessler, R. C. (2006). Risk factors for twelve-month suicide attempts in the national 
comorbidity survey replication (NCS-R). Psychology Medicine, 36(12), 17471757. DOI:

Bromet, E., Andrade, L. H., Hwang, I., Sampson, N. A., Alonso, J., Girolamo, G. d., Graaf, R. d., Demyttenaere, K., Hu, C., Iwata, N., Karam, A. N., et al. (2011). Cross-national epidemiology of DSM-IV major depressive episode. Bio Medicine Central, 9:90. http://www.biomedcentral.com/1741-7015/9/90.

Cattell, R. B. (1966). The scree test for the number of factors. Multivariate Behavioral Research, 1(2), 245-276. https://doi.org/10.1207/s15327906mbr0102_10.

Cohen, J. (1988). Statistical power analysis for the behavioral sciences $\left(2^{\text {nd }} e d.\right)$. Hillside, N.J.: Lawrence Erlbaum Associates.

Conner, K. R., Pinquart, M., \& Halbrook, A. P. (2008). Meta-analysis of depression and substance use and impairment among cocaine users. Drug and Alcohol Dependence, 98. DOI:10.1016/j.drugalcdep.2008.05.005.

Compton III, W. M., Cottler, L. B., Abdallah, A. B., Phelps, D. L., Spitznagel, E. L., \& Hotron, J. C. (2010). Substance dependence and other psychiatric disorders among drug dependent subjects: race and gender correlates. The American Journal on Addictions, 9 (2). https://doi.org/10.1080/10550490050173181.

Eduardo Fonseca-Pedrero, Craig Wells, Mercedes Paino, Serafín Lemos-Giráldez, Úrsula Villazón-García, Susana Sierra, Ma Paz García-Portilla González, Julio Bobes \& José Muñiz (2010) Measurement Invariance of the Reynolds 
Depression Adolescent Scale across Gender and Age, International Journal of Testing, 10:2, 133-148, https://doi.org/10.1080/15305050903580822.

Escobar, K. M., \& Gorey, K., M. (2018). Cognitive behavioral interventions for depression among Hispanic people: promising meta-analytic evidence for deep cultural adaptations. Social Work in Mental Health, 16(6), 746-758. DOI:10.1080/15332985.2018.1476284.

Dagher, R. K., \& Green, K. M. (2015). Does depression and substance abuse comorbidity affect socioeconomic status? Evidence from a prospective study of urban African Americans. Psychiatry Research, 225(0).

DOI:10.1016/j.psychres.2014.10.026.

Fava, M., Hwang, I., Rush, A.J., Sampson, N., Walters, E.E., \& Kessler, R. (2010). The importance of irritability as a symptom of major depressive disorder: results from the national comorbidity survey replication. Molecular Psychiatry, 15, 856-867.

Feldman, L. A. (1993). Distinguishing depression and anxiety in self-report: Evidence from confirmatory factor analysis on nonclinical and clinical samples. Journal of Consulting and Clinical Psychology, 61(4), 631638. https://doi.org/10.1037/0022-006X.61.4.631.

Friedrich, M. J. (2017). Depression is the leading cause of disability around the world. Global Health, 317(15), 1517. DOI:10.1001/jama.2017.3826.

Foulds, J. A., Adamson, S. J., Boden, J. M., Williman, J. A., \& Mulder, R. T. (2015). Depression in patients with alcohol use disorders: Systematic review and 
meta-analysis of outcomes for independent and substance-induced disorders. Journal of Affective Disorders, 185(1).

https://doi.org/10.1016/j.jad.2015.06.024.

Galea, S., Ahern, J., Tracy, M., \& Vlahov, D. (2007). Neighborhood income and income distribution and the use of cigarette, alcohol, and marijuana. American Journal of Preventative Medicine, 32.

Garlow, S. J. (2002). Age, gender, and ethnicity differences in patterns of cocaine and ethanol use preceding suicide. American Journal of Psychiatry, 159.

GBD 2017 Disease and Injury Incidence and Prevalence Collaborators. (2018).

Global, regional, and national incidence, prevalence, and years lived with disability for 354 diseases and injuries for 195 countries and territories, 19902017: a systematic analysis for the Global Burden of Disease Study 2017. The Lancet. https://doi.org/10.1016/S0140-6736(18)32279-7.

Gierisch, J. M., Bastian, L. A., Calhoun, P. S., McDuffie, J. R., \& Williams, J. W. (2011). Smoking cessation interventions for patients with depression: A systematic review and meta-analysis. Journal of General Internal Medicine, 27(3). https://doi.org/10.1007/s11606-011-1915-2.

Goodman, E., \& Huang, B. (2002). Socioeconomic status, depressive symptoms, and adolescent substance use. Archive Pediatric Adolescent Medicine, 150.

Gorka, S. M., Ali, B., \& Daughters, S. B. (2012). The role of distress tolerance in the relationship between depressive symptoms and problematic alcohol use. Psychology of Addictive Behavior, 26(3), 621-626. Doi:10.1037/a0026386. 
Green, K. M., \& Stuart, E. A. (2014). Examining moderation analyses in propensity score methods: Application to depression and substance use. Journal of Consulting Clinical Psychology, 82(5). DOI:10.1037/a0036515.

Goodman, E., \& Huang, B. (2002). Socioeconomic status, depressive symptoms, and adolescent substance use. Archive Pediatric Adolescent Medicine, 150.

Hankerson, S. H., Fenton, M. C., Geier, T. J., Keyes, K. M., Weissman, M. M., \& Hasin, D. S. (2011). Racial differences in symptoms, comorbidity, and treatment for major depressive disorder among black and white adults. Journal of National Medical Association, 103(7), 576-584. https://doi.org/10.1016/S0027-9684(15)30383-7.

Hayes, A. F., (2013). Introduction to mediation, moderation, and conditional process analysis: A regression-based approach. New York, NY: The Guilford Press.

Hedden, S., Gfroerer, J., Barker, P., Smith, S., Pemberton, M. R., Saavedra, L. M., Forman-Hoffman, V. L., Ringeisen, \& Noval, S. P. (2012). Comparison of NSDUH mental health data and methods with other data sources. Center for Behavioral Health Statistics and Quality. https://www.ncbi.nlm.nih.gov/books/NBK390286/.

Holahan, C. J., Moos, R. H., Holahan, C. K., Cronkite, R. C., \& Randall, P. K. (2003). Drinking to cope and alcohol use and abuse in unipolar depression: A 10-year model. Journal of Abnormal Psychology,112(1), 159-165.

DOI:10.1037/0021-843X.112.1.159. 
Hu, L.T., \& Bentler, P. M. (1999). Cutoff criteria for fit indexes in covariance structure analysis: Conventional criteria versus new alternative. Structural Equation Modeling: A Multidisciplinary Journal, 6(1), 1-55.

Humensky, J. L. (2010). Are adolescents with high socioeconomic status more likely to engage in alcohol and illicit drug use in early adulthood? Substance Abuse Treatment, Prevention, and Policy, 5(19).

Inaba, A., Thoits, P. A., Ueno, K., Gove, W. R., Evenson, R. J., \& Sloan, M. (2005). Depression in the United States and Japan: Gender, marital, status, and SES patterns. Social Science \& Medicine, 6, 2280-2292.

DOI:10.1016/j.socscimed.2005.07.014.

Karg, R. S., Bose, J., Batts, K. R., Forman-Hoffman, V. L., Liao, D., Hirsch, E., Pemberton, M. R., Colpe, L. J., \& Hedden, S.L. (2014). Past year mental disorders among adults in the United States: Results from the 2008-2012 mental health surveillance study. Center for Behavioral Health Statistics and Quality.

Karriker-Jaffe, K. J. (2013) Neighborhood socioeconomic status and substance use by U.S. adults. Drug Alcohol Dependency, 133(1), 212-221.

DOI:10.1016/j/drugalcdep/2013.04.033.

Kessler, R. C., Birnbaum, H., Bromet, E., Hwang, I., Sampson, N., \& Shahly, V. (2010). Age differences in major depression: Results from the national comorbidity surveys replication (NCS-R). Psychology Medicine, 40(2), 225243. DOI: 10.1017/S0033291709990213. 
Kessler, R.C., Berglund, P., Demler, O., Jin, R., Koretz, D., Merikangas, K. R., Rush, A. J., Walters, E. E., \& Wang, P.S. (2003). The epidemiology of major depressive disorder results from the national comorbidity survey replication (NCS-R). JAMA, 289(23), 3095-3105.

Kessler, R.C., Chiu, W.T., Demler, O., Merikangas, K. R., Walters, E.E. (2005). Prevalence, severity, and comorbidity of twelve-month DSM-IV disorders in the National Comorbidity Survey Replication (NCS-R). Archives of General Psychiatry, 62(6), 617-627.

Kessler, R.C., Berglund. P., Chiu, W. T., Demler, O., Heeringa, E. H., Jin, R., Pennell, B., Walters, E. E., Zaslavsky, A., \& Zheng, H. (2006). The US national comorbidity survey replication (NCS-R): design and field procedures. International Journal of Methods in Psychiatric Research, 13 (2), 69-92. https://doi.org/10.1002/mpr.167.

Kessler, R. C., Gruber, M., Hettema, J.M., Hwang, I., Sampson, BA., Yonkers, K. A. (2008). Comorbid major depression and generalized anxiety disorders in the national comorbidity survey follow-up. Psychology Medicine, 38(3), 365-374. DOI:10.1017/S00033291707002012.

Kuehner, C. (2003) Gender differences in unipolar depression: an update of epidemiological findings and possible explanations. Acta Psychiatrica Scandinavica, 108(3). https://doi.org/10.1034/j.1600-0447.2003.00204.x.

Lee, J. O., Herrenkohl, T. L., Kostermann, R., Small, C. M., \& Hawkins, D. (2013). Educational inequalities in the co-occurrence of mental health and substance 
use problems, and its adult socioeconomic consequences: A longitudinal study of adults in a community sample. Public Health, 127(8).

DOI:10.1016/j.puhe.2013.04.005.

Lu, Q., He, H., Yang, J., Feng, X., Zhao, F., Lyu, J. (2020). Changes in the global burden of depression from 1990 to 2017: Findings from the global burden of disease study. Journal of Psychiatric Research, 126, 134-140. https://doi.org/10.1016/j.jpsychires.2019.08.002.

Major depression. (2019, February). Retrieved February 17, 2021, from https://www.nimh.nih.gov/health/statistics/majordepression.shtml\#part_155029.

Mezuk, B., Raffrety, J. A., Kershaw, K. N., Hudson, D., Abdou, C. M., Lee, H., Eaton, W. W., \& Jackson, J. S. (2010). Reconsidering the role of social disadvantage in physical and mental health: Stressful life events, health behaviors, race, and depression. American Journal of Epidemiology, 172(11), 1238-1249. DOI:10.1093/aje/kwq283.

Mojtabai, R., Chen, L., Kaufmann, C. N., \& Crum, R. M. (2014). Comparing barriers to mental health treatment and substance use disorder treatment among individuals with comorbid major depression and substance use disorder. Journal of Substance Abuse Treatment, 46. http://dx.doi.org/10.1016/j.jsat.2013.07.012.

Marmorstein, N. R. (2009). Longitudinal associations between alcohol problems and depressive symptoms: Early adolescence through early adulthood. 
Alcoholism: Clinical and Experimental Research, 33(1). DOI:10.1111/j.15300277.2008.00810.x.

Moscato, B. S., Russell, M., Zielezny, M., Bromet, E., Egri, G., Mudar, P., \& Marshall, J. R. (1997). Gender differences in the relation between depressive symptoms and alcohol problems: A longitudinal perspective. American Journal of Epidemiology, 146(11).

Pemberton, M., R., Bose, J., Kilmer, G., Kroutil, L.A., Forman-Hoffman, V.L., \& Gfroerer, J. C. (2013). Comparison of NSDUH health and health care estimates to other national data sources. Center for Behavioral Health Statistics and Quality.

Peirce, R. S., Frone, M. R., Russell, M., Cooper, M. L., \& Mudar, P. (2000). A longitudinal model of social contact, social support, depression, and alcohol use. Health Psychology, 19(1), 28-38. DOI: 10.1037//0278-6133.19.1.28.

Poikolainen, K., Tuulio-Henriksson, A., Aalto-Setälä,T., Marttunen, M., Lönnqvist, J. (2001) Predictors of alcohol intake and heavy drinking in early adulthood: a 5year follow-up of 15-19-year-old Finnish adolescents, Alcohol and Alcoholism, 36(1), 85-88, https://doi.org/10.1093/alcalc/36.1.85

Poulin, C., Hand, D., Boudreau, B., \& Santor, D. (2004). Gender differences in the association between substance use and elevated depressive symptoms in a general adolescent population. Addiction, 100. DOI:10.1111/j.13600443.2005.01033.x. 
RStudio Team (2020). RStudio: Integrated Development for R. RStudio, PBC, Boston, MA URL http://www.rstudio.com/.

Rohde, P., Lewinsohn, P. M., Kahler, C. W., Seeley, J. R., \& Brown, R. A. (2001). Natural course of alcohol use disorders from adolescence to young adulthood. Journal of the American Academy of Child \& Adolescent Psychiatry, 40(1), 83-90. https://doi.org/10.1097/00004583-200101000-00020.

RStudio Team (2020). RStudio: Integrated Development for R. RStudio, PBC, Boston, MA URL http://www.rstudio.com/.

Ryan, T.A., Bailey, A., Fearon, P. and King, J. (2013), Factorial invariance of the Patient Health Questionnaire and Generalized Anxiety Disorder Questionnaire. Br J Clin Psychol, 52: 438449. https://doi.org/10.1111/bjc.12028.

Salas, J., Scherrer, J. F., Lustman, P. J., \& Schneider, F. D. (2016). Racial differences in the association between nonmedical prescription opioid use, abuse/ dependence, and major depression. Substance Abuse Journal, 37(1). DOI:10.1080/08897077.2015.1129523.

Sullivan, L. E., Fiellin, D. A., \& O'Connor, P. G. (2005). The prevalence and impact of alcohol problems in major depression: A systematic review. The American Journal of Medicine, 118. DOI:10.1016/j.amjmed.2005.01.007.

Sordo, L., Chahua, M., Barvo, M. J., Barrio, G., Brugal, M. T., Domingo-Salvany, A., Molist, G., Fuente, L. D., \& ITINERE Project Group (2012). Depression 
among regular heroin users: The influence of gender. Addictive Behaviors, 37. DOI:10.1016/j.addbeh.2011.09.009.

Substance Abuse and Mental Health Services Administration. (2012). Mental Health, United States, 2010. HHS Publication No. (SMA) 12-4681. Rockville, MD: Substance Abuse and Mental Health Services Administration.

Swendsen, J. D., \& Merikangas (2000). The comorbidity of depression and substance use disorder. Clinical Psychology Review, 20(2).

Tormohlen, K. N., Tobin, K. E., \& Latkin, C. (2019). Sources of stress among adults with co-occurring drug use and depressive symptoms. Journal of Urban Health, 96(3). https://doi.org/10.1007/s11524-018-0304-0.

U.S. Department of Health and Human Services, Substance Abuse and Mental Health Services Administration, Center for Behavioral Health Statistics and Quality. (2019). National Survey on Drug Use and Health 2018 (NSDUH-2018DS0001). Retrieved from https://datafiles.samhsa.gov/.

Wilkinson, A. L., Halpern, C. T., Herring, A. H., Shanahan, M., Ennett, S. T., Hussey, J. M., \& Harris, K. M. (2016). Testing longitudinal relationships between binge drinking, marijuana use, and depressive symptoms and moderation by sex. Journal of Adolescent Health, 59. http://dx.doi.org/10.1016/j.jadhealth.2016.07.010. 